\title{
Metaconsumo y la Biblia ${ }^{a}$
}

\author{
Víctor M. Armenteros ${ }^{2}$ \\ Universidad Adventista del Plata, Argentina² \\ Gestión de Vida Cristiana, Iglesia Adventista del Séptimo Día, España² \\ Orcid ID: https://orcid.org/0000-0003-1292-3243²
}

Recibido: 13 de noviembre de 2017

Aceptado: 03 de enero de 2018

\section{Resumen}

El objetivo de este artículo es encontrar las definiciones de los conceptos relacionados al metaconsumo, consumismo, hiperconsumo en los textos veterotestamentarios, y las propuestas y soluciones neotestamentarias. Se concluye de forma constructiva y exhortatoria las posibles actualizaciones que generen percepción y comprensión del mito en relación al metaconsumo y la Biblia.

Palabras clave: metaconsumo, consumismo, Biblia y consumismo, análisis veterotestamentario
Abstract
The objective of this article is to find the definitions of the concepts related to metaconsumption, consumerism and hyperconsumption in the Old Testament texts, and New Testament proposals and solutions. The conclusion offers constructive encouragement regarding possible updates that generate perception and understanding of the myth regarding metaconsumption and the Bible
Key-words: Metaconsumption, consumerism, Bible and consumerism, Old Testament analysis
Serán para mí especial tesoro, dice Jehová de los ejércitos, en el día en que yo actúe.

\footnotetext{
${ }^{a}$ Conferencia presentada en la XLIII Convención de la Asociación de Estudiantes y Graduados Adventistas de España, "Consumismo y cristianismo" en Alborache (Valencia, España) en diciembre del 2017.

${ }^{\mathrm{b}}$ Correspondencia al autor

E-mail: varmenteros@adventista.es
}

Metaconsumption and the Bible 
Los perdonaré como un hombre perdona al hijo que lo sirve. Entonces os volveréis y discerniréis la diferencia entre el justo y el malo, entre el que sirve a Dios y el que no le sirve.

(Mal 3,17-18)

En el marco de un enfoque "disperso", lo que hay que denunciar no es tanto el consumismo propiamente dicho como su hipertrofia, ese imperialismo que obstaculiza el desarrollo de la diversidad de los potenciales humanos. (Gilles Lipovetsky, "La felicidad paradójica")

Los nuevos dioses son celosos de sus intenciones y velan las miradas (Bauman \& Donskis, 2015a) de los creyentes con multitud de visiones, con los brillos de las cosas y la velocidad del momento. Así, la diosa Media exige tiempo y enfoque para que mutemos en periféricos eficientes. El dios Información se torna pasmoso en generosidad y nos bombardea de datos hasta la infoxicación y la superficialidad intelectual. La diosa Individualidad impone la tiranía de la subjetividad con el propósito de que la dispersión desdibuje identidades. El dios Placer, superando los espacios físicos, nos oferta la nueva tierra virtual para que el escapismo se torne en la alternativa a cualquier resiliencia. Y, cómo no, la diosa Consumo que, cual Medusa, coloca el amuleto apotropaico (sea gorgoneion o Versace) en cada uno de sus acólitos. Los que le rinden adoración se tornan pétreos y viven cosificados. Son dioses que se expresan, sin reparo alguno, a todas luces, ante una ceguera cognitiva, ignorada o aceptada, de multitudes.

Tal ejercicio de prepotencia amerita un análisis metacognitivo. Alejarse del hipnotismo de la bestia para identificarla y desmitificarla. No hay tiempo para el panteón en su totalidad y nos enfocaremos en una de las más poderosas, cuyo PIB define naciones y cuyos ciclos ctónico-económicos nos bambolean de expansión en recesión; reflexionaremos sobre Consumo. Nos enfrentaremos con las armas desmitificadoras del pasado: la historia revelada y la historia comprendida. Como diría Mircea Eliade (Eliade, 206, p. 112):

Tan sólo gracias al descubrimiento de la historia, y más exactamente, al despertar de la conciencia histórica del judeocristianismo y su desarrollo con Hegel y sus sucesores, tan sólo gracias a la asimilación radical de esta nueva manera de ser en el mundo que representa la existencia humana, se pudo superar el mito.

El itinerario se iniciará con las definiciones de los conceptos. Discurrirá por la historia y comprensión de los significados en los textos veterotestamentarios, y las propuestas y soluciones neotestamentarias. Y, finalmente, se sugerirá, de forma 
constructiva y casi exhortatoria, posibles actualizaciones que generen percepción y comprensión del mito.

\section{Definiciones de los conceptos}

El vínculo de los conceptos conectados con emere se asocia con actos como "tomar", "obtener", “asumir" e, incluso, “distribuir". De ahí que el verbo “consumir" se halle relacionado con la obtención conjunta de algo o alguien. Por esta razón, en nuestros días, también adquiere el significado de "extinguir".

\subsection{Consumo}

El sentido más básico hace a las necesidades fisiológicas que precisamos y que nos mantienen vivos. Quizá la mejor clarificación sea la que propone Zygmunt Bauman cuando indica (Bauman, 2016, p. 43):

En realidad, si se lo reduce a su forma arquetípica en tanto ciclo metabólico de ingesta, digestión y excreción, el consumo es una condición permanente e inamovible de la vida y un aspecto inalienable de ésta, y no está atado ni a la época ni a la historia. Desde ese punto de vista, se trata de una función imprescindible para la supervivencia biológica que nosotros, los seres humanos, compartimos con el resto de los seres vivos, y sus raíces son tan antiguas como la vida misma. No hay dudas que consumir es una parte integral y permanente de todas las formas de vida que conocemos, ya sea por los relatos históricos o por los informes etnográficos.

El ser humano, sin embargo, no sólo tiene necesidad de consumo biológico para mantenerse vivo sino que, a su vez, precisa consumo psicosocial para ser persona y consumo trascendente para que su existencia tenga significado. En el consumo psicosocial se precisará de la seguridad, de la continuidad de una historia de vida (identidad), del apego (vínculos afectivos) y de la relación con el grupo (inclusión). El consumo trascendente necesitará de la autorrealización (proyección y sentido de la vida), de comprensión espiritual, de actitud ética y de una cosmovisión que tenga un horizonte fundamentado en la esperanza.

\subsection{Consumismo}

El consumismo es a lo innecesario lo que el consumo a lo necesario. En palabras de Zygmunt Bauman (Bauman, 2016, p. 47):

Se puede decir que el "consumismo" es un tipo de acuerdo social que resulta de la reconversión de los deseos, ganas y anhelos humanos (si se quiere "neutrales" respecto del sistema) en la principal fuerza de impulso y de operaciones de la sociedad, una fuerza que coordina la reproducción sistémica, la integración social, la estratificación social y la formación del individuo humano, así como también desempeña un papel 
preponderante en los procesos individuales y grupales de autoidentificación, y en la selección y consecución de políticas de vida individuales.

De ahí que el consumo biológico se torne en consumismo biológico y, por ejemplo, comer no sea tanto una cuestión de nutrición sino un asunto de cultura gastronómica, placer o experiencia. El consumo psicosocial se convierte en consumismo psicosocial $\mathrm{y}$, por ejemplo, las asociaciones humanas derivan en expresiones de estatus y poder. El consumo trascendente se muta en consumismo trascendente y, por ejemplo, la ética se infantiliza.

Desde el estilo de vida ateniense hasta el Dubái Mall, pasando por los excesos de la dinastía Ming o de los zares rusos, ha penetrado en los intereses de las sociedades (McCabe, 2015; Trentmann, 2012; Witkowski, 2018). Sin embargo, Gilles Lipovetsky lo asocia con los dos primeros ciclos del capitalismo de consumo. El primero, que comienza en torno a 1880 y que concluye con la Segunda Guerra Mundial, se desarrolla cuando los mercados se extienden hasta llegar a ser nacionales gracias a los medios de transporte y comunicación, cuando surge la producción en masas debido a una organización científica del trabajo, cuando el producto se asocia con la mercadotecnia, cuando la relación con el minorista se rompe y se genera un consumidor de marcas, cuando los almacenes se convierten en los templos de la incipiente modernidad (Lipovetsky, 2014, p. 22-26). El segundo ciclo, desde 1950 hasta 1980, destaca por generar la "sociedad de la abundancia", por disparar de forma exponencial el poder adquisitivo, por incrementar las superficies comerciales, por normalizar la moda. En sus propias palabras (Lipovetsky, 2014, p. 31):

La fase II se anuncia como "sociedad del deseo", ya que toda la cotidianidad está impregnada del imaginario de la felicidad consumista, de sueños playeros, de ludismo erótico, de modas ostensiblemente juveniles, Música rock, tebeos, lolitas, liberación sexual, fun morality, diseño vanguardista: el período heroico del consumo rejuveneció, euforizó, aligeró los signos de la cultura cotidiana. Mediante mitologías adolescentes, liberacionistas y despreocupadas por el porvenir se llevó a cabo una profunda mutación cultural.

Y esa mutación cultural genera un nuevo enfoque de lo que resulta natural a la persona: consumir por consumir. Así lo expresaba Adela Cortina en una conferencia sobre Cristianismo y Justicia (Cortina, 2004, p. 5):

Así, pues, una sociedad consumista es aquella cuya dinámica central está constituida por los bienes de consumo superfluos; y en la que, además, la gente cifra su éxito y su felicidad en ese consumo. Esto es lo que ocurre en nuestras sociedades, en las que las gentes están convencidas de que tener éxito es poder lucir coches, vestidos, etc. Y esto 
es además lo que les proporciona felicidad. No es que la gente piense esto demasiado reflexivamente, pero es lo que realmente tienen en la mente. Por eso podemos decir que estamos en una sociedad consumista. Estamos en la era del consumo porque el consumo está en la médula de nuestras sociedades. En ese consumo "vivimos, nos movemos y somos". Nos parece que es lo natural y que lo artificial es cambiar ese estilo. Lo natural es que uno sale y se toma un refresco y entonces uno se compra esto, y se compra lo otro... jes lo natural!

Tal actitud demandará algunas reflexiones urgentes desde la plataforma biológica (¿Hay recursos suficientes en el planeta para esta dinámica?), psicosocial (¿Cuáles son las fronteras del consumismo? ¿Fortalece las asimetrías?) y trascendente (¿Consumimos o somos consumidos?).

\subsection{Hiperconsumismo}

El hiperconsumismo es a la experiencia de vida lo que el consumismo a lo innecesario. Tal y como expresa Lipovetsky (Lipovetsky, 2014, p. 36-37):

Entre las dinámicas que se pusieron en marcha hace medio siglo hay una que se ha vuelto dominante en el período del hiperconsumo, las motivaciones privadas prevalecen en gran medida sobre los objetivos de la distinción. Queremos objetos «para vivir» más que objetos para exhibir, se compra menos esto o aquello para enseñarlo, para alardear de posición social, que, pensando en satisfacciones emocionales y corporales, sensoriales y estéticas, comunicativas y sanitarias, lúdicas y entretenedoras. Los bienes comerciales que funcionaban sobre todo como símbolos de la posición se presentan de manera creciente como servicios a la persona. Esperamos menos que las cosas nos categoricen delante de los otros y más que nos permitan ser más independientes y móviles, paladear sensaciones, vivir experiencias, mejorar nuestra calidad de vida, conservar la juventud y la salud.

En el hiperconsumismo supera la estandarización para aproximarse a lo específico, a lo subjetivo, a la demanda individual, al consumo emocional, a la comunicación-necesidad. Es la llegada de un hipermaterialismo que convierte a las personas en homo consumericus (Saad, 2006, 2014), un ser tan volátil como insaciable, un ser que compra por placer, un ser enfebrecido con la constante novedad, un turboconsumidor policrónico. "El hiperconsumidor es ese individuo agobiado para quien el factor tiempo se ha vuelto un referente fundamental que decide la organización de la cotidianidad. Tras la obsesión de la honorabilidad social por los símbolos comerciales viene la compulsión de ganar tiempo. Estamos en el momento en que el ahorro del tiempo parece más importante que la economía teatral de los signos, en el momento en que la carrera contrarreloj puede más que la carrera por la estima." (Lipovetsky, 2006, p. 103). Tal hiperconsumidor, a su vez, se dispersa en multitud de "sumers" que perpetúan la cadena de atomizaciones. Como indicaba, realizando una 
taxonomía al momento, Carlos Ballesteros en la columna AlterConsumismo de El País (Ballesteros):

- Entre transumers o consumidores de "ahoras", intensos y prolongados. El 11 de septiembre de 2001 y las posteriores consecuencias del mismo, entre las que destaca el sentimiento de ser vulnerable, la crisis que nos hace sentirnos prescindibles y amenazados en lo que hasta ahora era nuestro valor primordial (el trabajo); el desapego de la clase política que, salvo honrosas excepciones, no vemos que trabaje para solucionar nuestros problemas cotidianos..... No hay futuro, carpe diem, consumamos ahoras porque no sabemos si habrá luegos.

- trysumers: consumidores con ganas de probar (try en inglés) nuevas cosas,

- localsumers: consumidores arraigados a sus consumos locales

- virginsumers o aquellos consumidores que, cada vez más frecuentemente, se encuentran con productos que no saben utilizar, procesos con los que no están familiarizados, marcas que no conocen...y sin embargo no se asustan ante ello y deciden experimentar, probar y comentar luego en las redes su experiencia.

- presumers: pre-consumidores. Personas que se involucran en el proceso de creación de los productos y servicios. La acelerada salida al mercado de versiones, modalidades de productos hace que en muchas ocasiones las empresas decidan lanzar versiones $\beta$ que son mejoradas y complementadas en y con el uso que hace el mercado de los mismos.

- Crowdsumers: consumidores que hacen uso de las plataformas crowd, tanto para beneficiarse de compras colectivas, compras en grupo, etc. como para participar en financiación de proyectos culturales o solidarios mediante aportaciones mínimas (pero masivas en número) @Crowdsumers

- Wikisumers o consumidores colaborativos que ejercen su derecho al consumo desde las maneras tradicionales de compartir, intercambiar, prestar, alquilar y regalar redefinida a través de la tecnología moderna y las comunidades. www.ouishare.net

- Knowcosters. Movimiento iniciado por Miguel Conde que plantea la necesidad de consumir como uno piensa, conociendo y siendo consciente, además de los costes visibles del producto (reflejados en el precio venta al público) de todos los costes indirectos, que no se ven y que pagamos todos: coste estado de bienestar y coste.

Un pensamiento los aúna: "Consumo, luego existo." Su fe se fundamenta en la Economía de la Felicidad (olvidando la paradoja de Easterlin). Pero no hay felicidad a mayor renta, ni la ansiedad abandona a los turboconsumidores, ni lo nuevo compensa lo esencial. Las cosas no nos hacen personas más plenas.

\subsection{Consumerismo}

El término "consumerismo" se bifurca en dos significados. El primero de ellos hace referencia a "un movimiento social que pretende incrementar el derecho y los poderes de los consumidores en relación con aquellos que tienen los vendedores" (Abascal Rojas, 2002; Kotler, 1978; Aaker, 1982). El segundo, aquella plataforma de pensamiento que considera el consumismo como una actividad que destruye tanto a la persona como a las instituciones. Tal planteamiento genera un consumo mejor pensado, más respetuoso con el planeta y con los seres humanos. Como indica Josep María Gali (Gali, 2013): 
En español hablamos de consumismo cuando queremos referirnos al consumo en sentido excesivo, hiperbólico y exagerado; de consumerismo cuando hablamos de un consumo basado en una actitud responsable, racional y sostenible. En Inglés (sic), solo existe el término "consumerism", que se usa para los dos significados, que hay que leer en función del contexto. En francés la palabra "consumerisme" también se usa en los dos sentidos, aunque normalmente cuando se habla de consumismo se habla de la "societé de consommation".

La búsqueda de la autosuficiencia y de las actitud colaborativa definen las líneas principales de acción de los consumeristas.

\subsection{Gestión integral}

Gestión integral es una modernización de expresiones antiguas del castellano (veedor, mayordomo, custodio, fideicomisario, apoderado, intendente, administrador) que hacen referencia al responsable, no dueño, de unos bienes. La gestión integral, por tanto, respondería al consumo equilibrado de nuestro planeta y de los seres que lo habitan.

La expresión inglesa "stewardship" llega a tener una fuerte connotación religiosa $\mathrm{y}$, además de en textos ecológicos, se relaciona con materiales que vinculan al ser humano con Dios como creador y poseedor del universo. En un entorno adventista la expresión ("mayordomía", "gestión de vida cristiana") responde tanto a los valores económicos como a los recursos relacionados con el tiempo, las capacidades, la influencia, la búsqueda de una existencia vital y la comunicación como un instrumento relacional. Como indica Walter R. L. Scragg (Scragg, 2017):

God delegated the appropriate powers and authorities to carry out stewardship. These, too, are a resource demanding our stewardship. What God is for the whole creation in ruling, sustaining, and caring, humanity was to be for this earth (Gen 1:26). The Christian views stewardship as a primary area in which the image of God may be effected through relationship to the world, other individuals, and the use ofall resources.

Desde una cosmovisión cristiana, el hiperconsumismo de nuestros días entra en conflicto con la moralidad, con la ética y el horizonte del ser humano. Se contempla, por tanto, desde una perspectiva escatológica (Pereyra, 2011).

\section{Antecedentes veterotestamentarios}

Una primera aproximación al metaconsumo en la Biblia se impone desde la argumentación por precedencia y los puntos de inflexión teológica en la Escritura. Son paradas ineludibles en este itinerario las propuestas de la Protología (Gn 1-3), el marco 
legislativo de la Torah (tanto como principios [10 mandamientos] como por propuestas reglamentarias [estatutos]) y el afrontamiento sapiencial (por no decir filosófico) de Qohélet.

\subsection{Protología}

Es la disciplina de la Teología que hace a los asuntos dedicados al origen de la historia o a la prehistoria (Collins, 1979, p. 6; Forte, 1995; Gage \& Waltke, 2001; Armenteros, 2016a, p. 92-111). Puede existir una Protología sin Escatología pero, es indudable que no puede existir una Escatología sin Protología. La Teología Adventista se enmarca desde sus orígenes en una Escatología bien definida y activa. Tal tendencia la condiciona a buscar las raíces de su Protología como generadora de principios interpretativos. En este sentido, el contenido del los tres primeros capítulos del Génesis se convierte en primordial en su doble sentido de primero y principal o esencial. De hecho, tal material vertebra la estructura de casi un tercio del texto genesiaco.

Desde la perspectiva del Metaconsumo podemos detectar la siguiente estructura en los relatos de Génesis 1-3:

\begin{tabular}{|c|c|c|c|c|}
\hline \multicolumn{2}{|c|}{ REFERENCIA } & RELATO & CONCEPTO & $\begin{array}{c}\text { NIVEL } \\
\end{array}$ \\
\hline \multirow[t]{10}{*}{1} & $3-5$ & Luz & \multirow{7}{*}{ Entorno ecológico } & \multirow{7}{*}{-} \\
\hline & $6-8$ & Firmamento & & \\
\hline & $9-10$ & Tierra - aguas & & \\
\hline & $11-13$ & $\begin{array}{l}\text { Hierba verde } \\
\text { Hierba semilla } \\
\text { Árbol fruto } \\
\text { Árbol semilla }\end{array}$ & & \\
\hline & $14-19$ & $\begin{array}{l}\text { Lumbreras - estrellas } \\
\text { a) Señorear }\end{array}$ & & \\
\hline & $20-23$ & $\begin{array}{l}\text { Seres marinos y aéreos } \\
\text { a) Fructificad y multiplicaos }\end{array}$ & & \\
\hline & $24-25$ & Seres terrestres & & \\
\hline & $26-28$ & $\begin{array}{l}\text { Persona } \\
\text { a) "Fructificad y multiplicaos" } \\
\text { b) "Llenad" la tierra } \\
\text { c) "Gestionen/gestionad" } \\
\text { d) "Gobernad" la tierra }\end{array}$ & \multicolumn{2}{|c|}{ Gestión integral } \\
\hline & 29 & Alimentación de la persona & \multicolumn{2}{|c|}{ Consumo biológico } \\
\hline & 30 & Alimentación de los animales & \multicolumn{2}{|c|}{ Consumo biológico } \\
\hline \multirow[t]{6}{*}{2} & 3 & $\begin{array}{l}\text { Creación del sábado } \\
\text { a) Creación de un tiempo especial } \\
\text { (bendito y santo) } \\
\text { b) Creación de un tiempo activo (seis } \\
\text { días) y de encuentro (sábado) }\end{array}$ & \multicolumn{2}{|c|}{ Consumo trascendente } \\
\hline & $5-6$ & Estructura hídrica (regadío) en general & \multirow{5}{*}{ Entorno ecológico } & \multirow{5}{*}{-} \\
\hline & 7 & Creación del hombre en general & & \\
\hline & 8 & Ubicación del jardín & & \\
\hline & 9 & Desarrollo de la vegetación & & \\
\hline & $10-14$ & Estructura hídrica (regadío) específica & & \\
\hline
\end{tabular}




\begin{tabular}{|c|c|c|c|c|}
\hline & 15 & $\begin{array}{l}\text { Creación específica del hombre } \\
\text { a) Labrar y cuidar }\end{array}$ & \multicolumn{2}{|c|}{ Gestión integral } \\
\hline & $16-17$ & Alimentación del hombre & \multicolumn{2}{|c|}{ Consumo biológico } \\
\hline & $18-20$ & $\begin{array}{l}\text { Actividad del hombre } \\
\text { a) Poner nombre a los animales } \\
\text { b) Proceso didáctico para una } \\
\text { necesidad de consumo psicosocial: } \\
\text { complementariedad. }\end{array}$ & \multicolumn{2}{|c|}{ Gestión integral } \\
\hline & $21-24$ & $\begin{array}{l}\text { Creación de la mujer } \\
\text { a) Definición y comprensión } \\
\text { antropológica } \\
\text { b) Relación } \\
\text { c) La mirada de la inocencia } \\
\end{array}$ & \multicolumn{2}{|c|}{ Consumo psicosocial } \\
\hline \multirow[t]{11}{*}{3} & $1-5$ & Diálogo entre la serpiente y la mujer & Entorno dialéctico & \\
\hline & $6 a$ & $\begin{array}{l}\text { Análisis del "producto" } \\
\text { a) "Bueno para comer" (producto apto } \\
\text { para el consumo biológico) } \\
\text { b) "Agradable a los ojos" (producto } \\
\text { apetecible) } \\
\text { c) "Deseable para alcanzar sabiduría" } \\
\text { (producto motivador para consumo } \\
\text { trascendente) } \\
\text { d) Toma y come (consumismo } \\
\text { trascendente) }\end{array}$ & \multicolumn{2}{|c|}{ Consumismo trascendente } \\
\hline & $6 b$ & $\begin{array}{l}\text { La mujer comparte el producto con su } \\
\text { marido. }\end{array}$ & \multicolumn{2}{|c|}{ Consumismo psicosocial } \\
\hline & 7 & $\begin{array}{l}\text { Primeros efectos del consumismo } \\
\text { a) La desnudez como resultado de la } \\
\text { mirada materialista. } \\
\text { b) La negación de la realidad y la } \\
\text { solución temporal. }\end{array}$ & \multirow{8}{*}{$\begin{array}{l}\text { Nuevo entorno } \\
\text { ecológico (efectos } \\
\text { del consumismo) }\end{array}$} & Efecto psicosocial \\
\hline & $8-10$ & $\begin{array}{l}\text { Segundo efecto del consumismo } \\
\text { a) La aparición del temor y de la } \\
\text { ansiedad. }\end{array}$ & & Efecto trascendente \\
\hline & $12-13$ & $\begin{array}{l}\text { Tercer efecto del consumismo } \\
\text { a) Locus de control externo } \\
\text { b) Generación y desplazamiento de la } \\
\text { culpa }\end{array}$ & & Efecto psicosocial \\
\hline & $14-19$ & $\begin{array}{l}\text { Anticipo de efectos posteriores } \\
\text { a) Involución de la naturaleza animal } \\
\text { b) La mujer como agente de } \\
\text { productividad y de heteronomía de } \\
\text { expectativas. } \\
\text { c) Alteración de la gestión del hombre } \\
\text { por procesos de mayor dificultad. }\end{array}$ & & $\begin{array}{l}\text { Efectos biológicos, } \\
\text { psicosociales y de } \\
\text { gestión. }\end{array}$ \\
\hline & 20 & $\begin{array}{l}\text { Adán pone nombre a Eva } \\
\text { a) Cosificación de la mujer } \\
\text { b) Estratificación al nivel de los } \\
\text { animales }\end{array}$ & & Efecto psicosocial \\
\hline & 21 & $\begin{array}{l}\text { Vestidos para Adán y Eva } \\
\text { a) Solución al problema psicosocial } \\
\text { b) Solución al problema trascendente } \\
\text { (tipología) }\end{array}$ & & $\begin{array}{c}\text { Respuesta psicosocial } \\
\text { y trascendente }\end{array}$ \\
\hline & 22 & $\begin{array}{l}\text { Impedimento a tomar del fruto del } \\
\text { árbol de la vida } \\
\text { a) Solución al problema biológico }\end{array}$ & & Respuesta biológica \\
\hline & $23-24$ & Nueva ubicación de la persona & & \\
\hline
\end{tabular}


Hay algunos procesos que se suelen identificar como comunes. Los tres relatos comienzan con una introducción narrativa, dos de corte ecológico $(1,3-23 ; 2,5-14)$ y uno dialéctico (3, 1-4). Se observa, además, que cualquier tipo de consumo viene precedido de proposiciones con relación a la gestión integral. Podemos, por tanto, indicar que el itinerario narrativo sigue una ruta de lo general a lo específico, estando el consumo muy vinculado con la gestión.

En el primer capítulo nos encontramos con un planteamiento del entorno ecológico del proceso creativo desde una perspectiva biológica. Con la creación de la persona (recordemos que אדָָ - 'ädäm no lleva artículo por lo que hace referencia a la totalidad del ser humano, la suma de lo masculino y lo femenino) se establecen las pautas de una gestión integral. Cuatro son las propuestas:

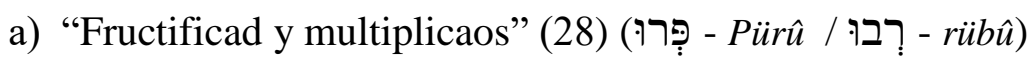

Ambos términos se expresan en imperativo y responden a un mandato divino. El vocablo গִִ̣ Pürû se asocia con el hecho de "llevar fruto" o cualquier tipo de producto resultante de una cosecha. Según James Swanson (Swanson, 1997) el término implica "ser fructífero" y se asocia con el concepto de abundancia (Gn 1,22). También se relaciona con el sentido de "hacer fructificar". En tal sentido véase Gn 17,6.20; 28,3; 41,52; 48,4; Lv 26,9; S1 105,24. Francis Brown, Samuel Rolles Driver y Charles Augustus Briggs (Brown, Driver \& Briggs, 2000) añaden el matiz de "llevar fruto". Wilhelm Gesenius y Samuel Prideaux Tregelles (Gesenius \& Prideaux, 2003) optan por el sentido genérico de "llevar". David A.J. Clines (Clines, 2011) añade a los significados anteriores el de "incrementar". En esta línea se posiciona Luis Alonso Schökel (Alonso, 1994) cuando menciona el término "cundir".

El término רִּ - rübû tiene el sentido de "ser numeroso", "incrementarse". Ambos discurren entre un significado cuantitativo y cualitativo. Swanson (Swanson, 1997) presenta varios sentidos: "Ser numeroso" (Gn 1,22; Jc 9,29; S1 44,13), "causar crecimiento" (Gn 17,2), “prosperar" (Job 39,4; Ez 16,7), “criar” (Ez 19,2), “ser grande” (1S 14,30; Job 33,12), “engrandecerse" (Esd 10,13; Dn 11,39), "ser distante" (Dt 14,24), "prolongarse en el tiempo" (1S 7,2) y "continuar" o "mantener" (1S 1,12). Brown (Brown, Driver \& Briggs, 2000) añade los sentidos de "ser" y "llegar a ser". Gesenius (Gesenius \& Prideaux, 2003) sigue el tradicional sentido de "multiplicarse". Clines (Clines, 2011), tras una detallada exposición de los significados previos, indica que sin objeto directo implica un incremento tanto de descendencia como de bienes. El 
más clarificador es Alonso Schökel (Alonso, 1994) que clasifica el uso en crecimiento en tamaño, número, cantidad, intensidad, grandeza y poder. Como indica Armenteros (Armenteros, 2010, p. 70-73):

El texto de Gn 1,28 ("Fructificad y multiplicaos") se puede comprender desde dos perspectivas, una física y otra existencial. La primera hace referencia a uno de los dones que más nos asemeja a la divinidad: la capacidad de procrear. Existen milagros cotidianos que, por su frecuencia, nos parecen comunes pero son sumamente singulares. Dar vida es uno de ellos... La primera expresión del texto es "fructificad" (Pürû) y, como indica la raíz en castellano, hace referencia a dar frutos. Una relación normal de pareja se desarrolla en un entorno de fertilidad, se produce como resultado de la suma de dos personas pletóricas de vida. El matrimonio es un proyecto que genera otros proyectos. Uno de ellos, indudablemente, son los hijos... El Señor nos anima a generar familias, familias con tiempo holgado para el afecto, la relación, el desarrollo, el equilibrio. Familias unidas por el vínculo invisible de la amistad, de la generosidad, de la lealtad. Familias que comparten proyectos y que se apoyan para conseguirlos. Familias que "disfrutan" juntos (permitidme el juego de palabras entre "fructificar" y "disfrutar", me hace bien) ... Una familia no sólo debe crecer en cantidad sino en calidad. La segunda expresión de Gn 1,28 es de un intenso espíritu mediterráneo. Dios quiere que nos multipliquemos, que seamos multitud. El Señor nos ha dado dones de sobra como para que los desarrollemos por la eternidad. Estamos diseñados para ser exponenciales. No hablamos de una simple suma de días, o la multiplicación de nuestras monedas o posesiones. Hablamos de la potencia de nuestro potencial. No somos dioses, ni mucho menos, pero somos "imagen" y "semejanza" de Dios. Esta sociedad nos encorseta en sus intereses. Nos convierte, por culpa de una competitividad feroz, en anodinos y, luego, nos convence de que nos estamos desarrollando al ser, simplemente, usuarios. ¿Ser usuario es el fin último del hombre? No, no es así... "Multiplicaos" implica la constatación de lo mucho que ha puesto el Señor dentro de nosotros, del potencial que dormita en nuestros genes. Dios nos alienta a despertar lo mejor que tenemos y compartirlo con nuestra gente, con nuestra pareja, con nuestra familia.

El primer par de mandatos se enfoca en el desarrollo y crecimiento de la raza humana, en la concreción del potencial tanto reproductivo como creativo. Son funciones de economía doméstica.

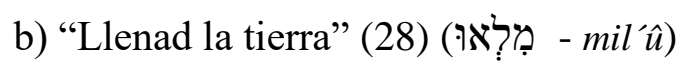

El tercer imperativo, al igual que los anteriores, tiene tanto una connotación cuantitativa como cualitativa. Swanson (Swanson, 1997) asocia el término con el hecho de "completar un espacio" (Gn 1,22), de "finalizar un período" (Gn 29,27), "comunicar abundantemente" (Job 32,18; S1 71,18; Jr 4,5), “satisfacer” (Ec 6,7; Ez 26,2), “tener plenitud" (Ec 1,8) o realizar algo con “todo el corazón”, con "total dedicación” (Nm 14,24). En estos sentidos se enmarcan Brown (Brown, Driver \& Briggs, 2000) y Gesenius (Gesenius \& Prideaux, 2003). Clines (Clines, 2011), de nuevo, se explaya en multitud de detalles con relación a los sentidos previos. Añade el de "completamente confiable" en la literatura del Sirácida (Si 4,17) y el de "consagrado como sacerdote" (el 
que recibe las manos llenas) en el sentido de plenitud (Ez 43,26). Alonso Schökel (Alonso, 1994) lo asocia con los términos "lleno", "plenitud", "totalidad", "multitud" y “capacidad". "Llenad", por tanto, se puede asociar con el hecho de crecer en número de habitantes o de extender el modelo del "jardín del Edén" a toda la tierra, el de expandir el proyecto creativo de Dios. Como indica Ellen G. White (White, 2008, p. 25-26):

El hogar de nuestros primeros padres había de ser un modelo para cuando sus hijos saliesen a ocupar la tierra. Ese hogar, embellecido por la misma mano de Dios, no era un suntuoso palacio. Los hombres, en su orgullo, se deleitan en tener magníficos y costosos edificios y se enorgullecen de las obras de sus propias manos; pero Dios puso a Adán en un huerto. Esta fue su morada. Los azulados cielos le servían de techo; la tierra, con sus delicadas flores y su alfombra de animado verdor, era su piso; y las ramas frondosas de los hermosos árboles le servían de dosel. Sus paredes estaban engalanadas con los adornos más esplendorosos, que eran obra de la mano del sumo Artista.

Les propone funciones de gestión artística y de creación de espacios de belleza. Algo así como la labor de un paisajista.

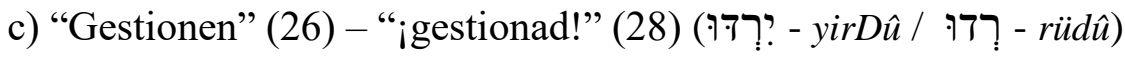

El término suele relacionarse con vocablos en español que hacen referencia al dominio, señorío o sometimiento. Depende del origen que se le asigne al lemma de tal término puede variar el campo semántico desde "sojuzgar" (Is 45,1) pasando por “mandar", "gobernar" (Nm 24,19; 1R 5,4.30; 9,23; Is 14,2; Ez 29,15; S1 72,9; 110,2) en el caso de los alomorfos דדר y רדה (Alonso, 1994, p. 690). O bien, el sentido de "estar a cargo" de bienes que están protegidos y sobre los que se tiene una responsabilidad, en el caso de provenir de ירד (literalmente "descender") en Clines (Clines, 2011, p. 419). Unificando ambos conceptos, se propone el empleo del vocablo "gestionar" porque involucra un compromiso sobre algo o alguien pero no implica su posesión sino su administración. Está claro que responde a una estructura vertical en la que el mundo animal y vegetal depende de los seres humanos. Como indica Ellen G. White (White, 2008, p. 25):

Adán fué colocado como representante de Dios sobre los órdenes de los seres inferiores. Estos no pueden comprender ni reconocer la soberanía de Dios; sin embargo, fueron creados con capacidad de amar y de servir al hombre. El salmista dice: "Hicístelo enseñorear de las obras de tus manos; todo lo pusiste debajo de sus pies: ... asimismo las bestias del campo; las aves de los cielos, ... todo cuanto pasa por los senderos de la mar." Salmos 8:6-8. 
Esta función respondería al acto de dirigir (sentido primitivo de los verbos) y administrar el planeta. No tiene implicaciones negativas en este contexto. De hecho, para matizar de forma negativa el verbo se le debe anexionar la expresión "con dureza"

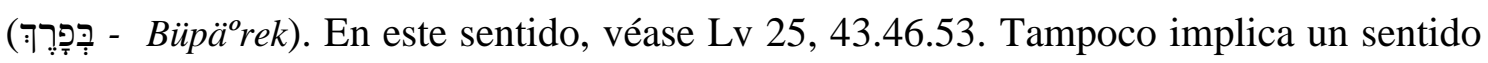
de expolio o de abuso. Como indica Steve W. Lemke (Cabal et al., 2007, p. 777):

Our having dominion over nature should not be confused with our owning nature. Humans do not own nature, because the earth is the Lord's (Lv 25:23; Ps 24:1; 50:1011). We are given the natural world as a stewardship, not as a possession... Nature is good because it was created by God and pleases God (Gn 1:1-31). God designed the natural world with an orderly structure, and violating that natural order is sinful $(\mathrm{Rm}$ 1:26-27).

O como expresa Dan Story (Story, 1997, p. 204):

It needs to be understood that the natural environment in wich God placed Adam and instructed him to be caretaker was a paradise that required no exploitation for Adam to survive. So whatever the words subdue and dominion mean in Genesis 1:28, they definitely do not convey enviromental exploitation. The Bible never grant us a license to abuse and manipulate nature. Instead, it promotes stewardship. This concept is best illustrated in the parable of the talents (Matt. 25:14-30). The biblica definition of stewardship is caring for someone else's property whith the goal of improving that property. Thus dominion, with regard to the environment, means caring for nature, and we do not own what we care for. So we are not free to use nature contrary to His wishes. And from all that we have seen, God wishes nature to be protected, to be taken care of.

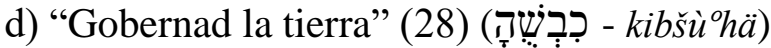

El término se relaciona con el vocablo כבש que hace referencia al cordero y a la domesticación del rebaño. En este sentido estaría muy cerca de nuestro término "gobernar" que implica mandar con autoridad, proveer lo necesario o ejercer una fuerte influencia. Aunque se registra con sentidos de "ser dependiente de alguien" tiene un matiz de cuidado. Como indica James E. Smith (Smith, 1993, p. 63):

Man was subdue (kabbash) the earth. The verb means to bring under one's control or take possession of a hostile country ( $\mathrm{Nm} 32: 22,29)$, enemies or slaves (2 Chron 28:10; Jer 34:11; Neh 5:5); to assert one's superiority of power or wisdom over another. Several of the twenty-four passages where this term is used in the Old Testament suggest that the dominion should be exercised with great care. The text suggest that it is throught multiplication of his race that man is to carry out his command to subdue the earth (1:28).

What are the implications of this creation mandate? Man is the crown of creation. Everything was made for him. God intended for man to develop all the potentialities of the earth. Any animal and plant forms may be freely sacrificed for the good of man. Of course this is no license to rape the earth. The authority is not absolute; it is delegated. Man is responsible to the Creator for the manner in which he interacts with his environment. 
El texto genesiaco, en el concepto de gestión integral, se proyecta en cinco etapas. Primero, propone el desarrollo de la familia por medio de la procreación y de los vínculos de sangre y proyectos. Segundo, el crecimiento de tales familias tanto en número como en potencialidades. Tercero, propone el desarrollo estructural que culmina con la población de la tierra y con la expansión del modelo edénico, el objetivo de convertir todo el planeta en un jardín. Cuarto, apuesta por la instauración de estructuras de autoridad donde la persona es el culmen de la cadena biológica y tiene el control del mundo. Quinto, la gestión de los seres vivientes, estando a cargo de sus necesidades y prestándoles la atención adecuada.

Tras el material sobre gestión nos encontramos con dos versículos que hacen referencia al consumo biológico: la alimentación de la persona (29) y la de los animales (30). Ambos dependientes de la plataforma vegetal aunque en diferentes niveles de la cadena trófica.

Génesis 2, 1-4 concluye la perícopa incorporando un concepto de consumo trascendente: el sábado. Se presenta la creación de un tiempo especial que tiene las características de ser bendito y santo, una oferta pública y especial. A su vez, se genera la disposición del tiempo activo de la semana (seis días) y el tiempo de encuentro (sábado) que responde a un consumo que trasciende a la actividad de gestión y que permite la relación divino-humana. En palabras de Ellen G. White (White, 2008, p. 2829):

Al bendecir el séptimo día en el Edén, Dios estableció un recordativo de su obra creadora. El sábado fué confiado y entregado a Adán, padre y representante de toda la familia humana. Su observancia había de ser un acto de agradecido reconocimiento de parte de todos los que habitasen la tierra, de que Dios era su Creador y su legítimo soberano, de que ellos eran la obra de sus manos y los súbditos de su autoridad. De esa manera la institución del sábado era enteramente conmemorativa, y fué dada para toda la humanidad. No había nada en ella que fuese obscuro o que limitase su observancia a un solo pueblo... Dios vió que el sábado era esencial para el hombre, aun en el paraíso. Necesitaba dejar a un lado sus propios intereses y actividades durante un día de cada siete para poder contemplar más de lleno las obras de Dios y meditar en su poder y bondad. Necesitaba el sábado para que le recordase más vivamente la existencia de Dios, y para que despertase su gratitud hacia él, pues todo lo que disfrutaba y poseía procedía de la mano benéfica del Creador.

El segundo bloque narrativo comienza, nuevamente, con la descripción del entorno ecológico $(2,5-14)$. En primer lugar menciona la estructura hídrica desde una perspectiva general, anticipando la labor de agricultor del primer hombre. Continúa con el relato de la creación de Adán y su ubicación en el jardín, del que se indica como existe un desarrollo de la vegetación. Pasa a una mayor especificidad narrativa y vuelve 
a describir la estructura hídrica. Es entonces, tras el marco contextual, que presenta de nuevo la labor de gestión del hombre (respondiendo al mandato de "gobernar" la tierra).

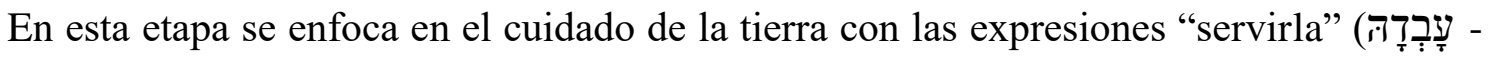

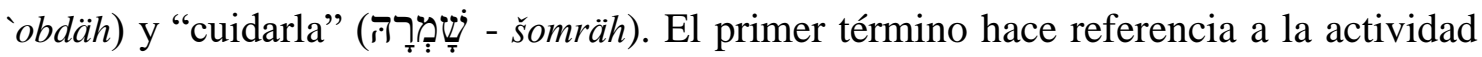
laboral, al trabajo mientras que el segundo implica, además de una actividad de especial atención, la función de protección y custodia.

En los versículos 16-17, reproduciendo una estructura paralela a Gn 1, se vuelve a mencionar el consumo biológico del hombre. Se incluyen nuevas funciones de su cometido (respondiendo al mandato de "gestionar"). En primer lugar, colocar nombre a los animales. Tal actividad, además de establecer una estructura taxonómica, otorga autoridad al hombre. Colocar los nombres de los animales, además de hacerlo copartícipe del proceso de la creación, indica el conocimiento de la esencia de lo denominado y análisis de la potencialidad de dicho ser. En el Antiguo Testamento, el acto de poner nombre era asignado a uno de los padres y solía ser de forma individual (Freedman, Meyers \& Beck, 2000). Además, se enfrentará a un proceso didáctico de análisis de su naturaleza que le permitirá comprender su necesidad psicosocial de un par de su tipo, de un ser complementario. Con la creación de la mujer se suple dicha necesidad y se produce una manifestación de consumo psicosocial. Tal y como indica Ellen G. White (White, 2008, p. 26):

Después de la creación de Adán, toda criatura viviente fué traída ante su presencia para recibir un nombre; vió que a cada uno se le había dado una compañera, pero entre todos ellos no había "ayuda idónea para él." Entre todas las criaturas que Dios había creado en la tierra, no había ninguna igual al hombre. "Y dijo Jehová Dios: No es bueno que el hombre esté solo, haréle ayuda idónea para él." Génesis 2:18. El hombre no fué creado para que viviese en la soledad; había de tener una naturaleza sociable. Sin compañía, las bellas escenas y las encantadoras ocupaciones del Edén no hubiesen podido proporcionarle perfecta felicidad. Aun la comunión con los ángeles no hubiese podido satisfacer su deseo de simpatía y compañía. No existía nadie de la misma naturaleza y forma a quien amar y de quien ser amado.

De ahí la definición de su par (sin otorgarle nombre porque no existe autoridad ni posesión) y la comprensión antropológica. Además de la percepción epistemológica, se produce una comprensión de la interrelación hombre-mujer. El autor concluye la narración con el concepto de "mirada inocente" para clasificar el tipo de consumo psicosocial que se produce. Una relación auténtica, sincera y carente de consumismo.

El tercer bloque narrativo comienza de forma diferente a los dos anteriores. Presenta un entorno dialéctico entre la serpiente y la mujer (Gn 3,1-5). El diálogo entre 
ambas marca la contextualización que permite comprender la reacción de la mujer. Nos muestra, además, las diferentes etapas del primer consumismo trascendente (6a) y psicosocial (6b):

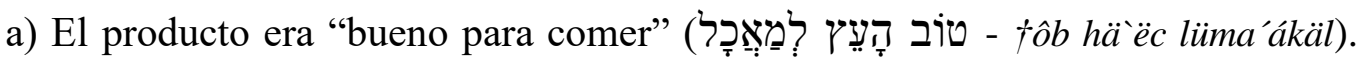
Recordemos que la expresión "bueno" (טוֹ - †ôb) no solo hace referencia a su cualidad nutrimental (bueno para comer) sino a su característica nutricional (útil en la alimentación). Respondería a una función básica en el consumo biológico. Nada objetable.

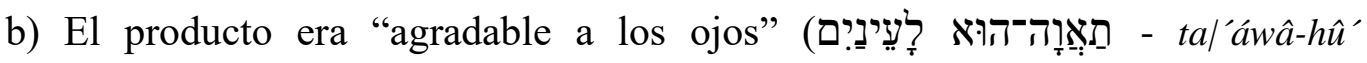
lä êna yim). El vocablo “agradable” (תַאְאָה - ta|'áwâ) entraría en el sentido de lo apetecible, de lo deseable (Sl 21,3) como de lo delicioso o delicado (Job 33,20). El trastoque de necesidad en deseo es el origen del consumismo. En este caso la necesidad alimentaria se torna más atractiva por la apetencia, el apetito sustituye al hambre. Como indica Massimo Ragnedda (Ragnedda, 2008):

Existe, de hecho, una enorme diferencia entre consumo y consumismo. El primero está asociado al comportamiento de quien adquiere unos «bienes» en función de su necesidad real, y de quien por lo tanto está ubicado en el espacio-tiempo real en el que vive, y no en la hiperrealidad en la que cree vivir. El consumismo es, sin embargo, la situación en la que la adquisición de los productos está determinada por falsas necesidades, por deseos inducidos, por los «status symbol» recibidos del exterior y generados por una publicidad que cada vez tiene menos relación con el producto en sí. Adquisición de productos que no sirven para satisfacer necesidades reales y concretas, pero cuya posesión hace sentir al sujeto que está al día o que pertenece a una determinada realidad social.

La mujer ve el producto agradable porque el deseo de cambiar de realidad se comienza a hacer patente. La hiperrealidad de la mujer se relaciona con un alejamiento de su realidad de criatura.

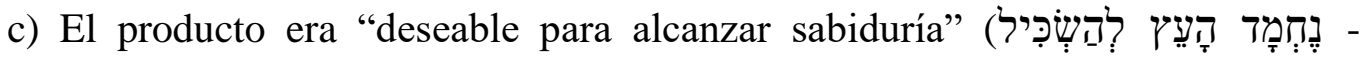
neHmäd hä ëc lühaSKîl). Nos hallamos ante dos términos sumamente interesantes. En

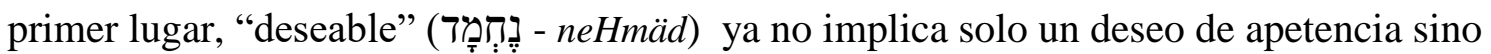
de posesión, de codicia. De hecho, procede del mismo lemma que hallamos en Ex 20,17 y Dt 5,21 cuando hace referencia a no codiciar. Se vincula con el deseo de plata (Dt 7,25), de un botín (Jos 7,21), de la belleza (Pr 6,25; Ez 23,6.12.23) o de campos de labranza (Miq 2,2). En segundo lugar, "sabiduría" (הָשְְָּׁיל - haSKîl ), expresión que tiene un sentido de conocimiento pero, a su vez, de prosperidad (Dt 29,9; Jos 1,7-8; 1S 18,30; 
2R 18,7). Tal actitud refleja un consumismo trascendente puesto que anhela de forma enfática una condición que no le es natural.

d) La mujer realiza el acto de "tomar" (derivado del anhelo de codicia) y "comer" (inicio de una espiritualidad mágica). Dicho acto concreta el consumismo trascendente.

e) La mujer comparte el producto con su marido. El consumismo trascendente precisa, además, de consumismo psicosocial. El consumismo, en este caso, se asocia con la identidad social, con la necesidad de pertenencia a una estructura colectiva. En este caso, la pareja. Desde entonces, el consumismo psicosocial se torna consumo de identidad. Como afirma Massimo Desiato Rugai Rugai, 2001, p. 149):

Podemos afirmar que el individualismo posesivo, definido, según nuestros fines, como aquella actitud en la cual el hombre alcanza su individualidad sólo a través de una posesión reducida a mero consumo de bienes con miras a impresionar el otro y obtener así su aprobación, se origina a partir de una característica peculiar y específica de la cultura moderna, a saber, el hecho de que la sociedad moderna se caracteriza por la omnipresencia del intercambio y del dinero en los diversos ámbitos de la vida social, y al mismo tiempo, por la coincidencia de la propiedad con la riqueza de ambas por tener derecho sobre las cosas.

De forma inmediata, tal consumismo genera un nuevo entorno ecológico. El primer efecto es de índole psicosocial surgiendo el concepto de desnudez como resultado de una mirada materialista. La mirada del amor que se origina en la inocencia y que se adorna de connotaciones se opone a la mirada del pecado que destaca lo irregular, lo meramente descriptivo. Además, se niega la realidad y se buscan soluciones temporales ante la irregularidad psicosocial. Delantales de hoja de higuera son respuestas a lo que se ve (por eso solo delantales) y a lo primero que hay a mano (lo inmediato como herramienta de urgencia). El segundo efecto es trascendente porque aparecen emociones desconocidas hasta el momento como el temor y la ansiedad. Así lo indicaba Salomón en Eclesiastés 5,10: "Quien ama el dinero, de dinero no se sacia. Quien ama las riquezas nunca tiene suficiente. ¡También esto es absurdo!” (NVI). O como dirán Luis Enrique Alonso Benito y Carlos Jesús Fernández Rodríguez (Alonso Benito \& Fernández Rodríguez, 2013):

La vida consumidora es así, según este autor [Bauman], una montaña rusa donde el comprador pasa por altibajos emocionales y vitales continuos a una enorme velocidad y sin permanecer un tiempo socialmente significativo en la cumbre (Bauman, $2006 \mathrm{y}$ 2007a). La lucha por la singularidad -el anhelo de la subjetividad- se ha convertido así, según Bauman (2005a), en el principal motor tanto de la producción como del consumo de masas. La lógica del consumismo va encaminada a satisfacer las necesidades de los 
hombres y las mujeres que se esfuerzan por construir, preservar y renovar su individualidad. Un proceso como este, inestable por definición, genera inmediatamente inseguridades respecto a la imagen conseguida, provocando más actos de compra y más deseos de emular las pautas dominantes de la cultutra comercial. En este marco de exceso, decisión e incertidumbre, las vidas de consumo son vidas para el consumo, en un permanente proceso de búsqueda de atributos e identidades inciertas que nunca acaban de consumarse (ya que el tiempo acelerado de la compra deja inmediatamente obsoletas las opciones de consumo disponibles, y sean cuales sean estas opciones efectivamente realizadas, siempre quedarán otras obras por hacer, hasta un punto inalcanzable).

El tercer efecto del consumismo es, de nuevo, de índole psicosocial. Los actantes del pecado desarrollan un intenso locus de control externo, no asumiendo la responsabilidad de sus actos. Se le añade, además, la generación del concepto de culpa y su desplazamiento hacia el otro.

De los versículos 14 al 19, en una prolepsis divina, tenemos un anticipo de algunos de los efectos (tanto biológicos, psicosociales como de gestión) que se producirán en el futuro. En primer lugar, una involución de la naturaleza animal dejando claro que la gestión del ser humano sobre los otros seres vivos se atendrá a variaciones imprevistas. El segundo, la mujer se convierte en un agente de productividad y objeto de cosificación que genera dependencia del hombre para que sus expectativas sean cumplidas. El hombre padecerá los rigores de la improductividad de la tierra al no poder "gobernarla" como en el planteamiento original.

Son de destacar los efectos psicosociales que se producen en el versículo 20 con relación a los vínculos hombre-mujer. Adán pone nombre a Eva lo que es un indicio de la imposición de su autoridad y, en cierta medida, del ejercicio de posesión. En este sentido, estratifica a Eva al nivel de los animales y la vincula con la productividadfertilidad.

Dios reacciona ante tales efectos con una respuesta tanto para los efectos psicosociales como trascendente: viste a Adán y Eva. Tal acción elimina la posibilidad de la mirada materialista y genera una solución real al problema del pecado: la muerte sustitutoria y la tipología que la acompaña. También aborda una solución como respuesta biológica a una larga vida en un entorno de irregularidad, impide el acceso al fruto del árbol de la vida y saca a Adán y a Eva del Edén para situarlos en un nuevo espacio terrenal. El proyecto del Jardín del Edén queda aparcado mientras se resuelve el problema del pecado.

Tales desarrollos narrativos nos llevan a algunas conclusiones:

a. Los tres relatos se introducen con un contexto, sea ecológico o dialéctico, 
que enmarca al ser humano, debido a las descripciones específicas, en un tono desmitificador y con visos de historicidad.

b. Cada propuesta de consumo es precedida por la enumeración de las funciones de la persona en un marco de gestión integral (implica las tres plataformas: biológica, psicosocial y trascendente).

c. El primer bloque narrativo presenta funciones del ser humano que se expresan tanto cuantitativa como cualitativamente. Además, propone una proyección del modelo edénico a toda la tierra y una gestión equilibrada de la vida animal.

d. El ser humano es responsable, garante y gestor del planeta Tierra. No está en posesión de este mundo y, por tanto, se debe a un ejercicio eficiente $\mathrm{y}$ preocupado de los seres y estructuras a su cargo. No hay, en este sentido, permiso para ningún tipo de expolio o abuso.

e. El consumo biológico responde a las necesidades de personas y animales.

f. La necesidad psicosocial de la mujer se constata didácticamente ya que no existe animal complementario al hombre. La interrelación de ambos seres se establece en paridad, autenticidad e inocencia.

g. El proceso de caída del ser humano es análogo a un proceso de consumismo. De la etapa natural de consumo biológico se produce una deriva hacia lo innecesario por el deseo $\mathrm{y}$, posteriormente, codicia de condiciones trascendentes que no caracterizan a la persona.

h. Al consumismo trascendente se le añade el consumismo psicosocial (el hombre elige compartir el acto consumista de la mujer) que tiene implicaciones de identidad social.

i. El consumismo tiene efectos inmediatos que van de lo externo (desnudez, mirada materialista) a lo interno (temor, ansiedad), de la alienación individual (locus de control externo) al desapego social (generación y desapego de culpa). Adán, además, cosifica a Eva y la considera una posesión.

\subsection{Torah}

Una aproximación a los textos legales en el Antiguo Testamento debe originarse de forma ineludible en las 10 palabras (Ex 20 - Dt 5), generadoras tanto de principios como de reglamentos posteriores. Una de las propuestas de vida se enfoca directamente 
en una de las irregularidades que genera el consumismo. El denominado décimo mandamiento vuelve a emplear el término que se refería a la mujer ante el fruto deseado

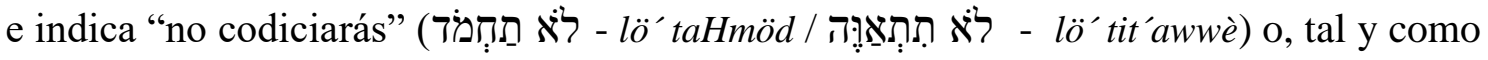

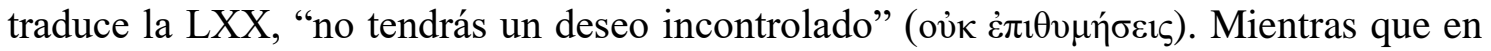
Éxodo 20 repite en dos ocasiones el mismo lemma (חמד), en Deuteronomio 5 propone dos raíces (אוה - חממד). La primera ya ha sido comentada, la segunda tiene el sentido de un "deseo ansioso" tanto en relación con la comida (Dt 12,15.20.21) como con la sexualidad (Jr 2,24). Es un deseo más cosificador que el primero. Una mirada sintética de ambos textos nos revela la evolución del pueblo hebreo en los años del desierto.

\begin{tabular}{|c|c|c|c|c|c|c|c|}
\hline \multicolumn{4}{|c|}{ Éxodo 20, 17} & \multicolumn{4}{|c|}{ Deuteronomio 5,21 } \\
\hline \multicolumn{2}{|c|}{ Acción } & \multicolumn{2}{|c|}{ Objeto } & \multicolumn{2}{|c|}{ Acción } & \multicolumn{2}{|c|}{ Objeto } \\
\hline 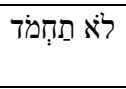 & $\begin{array}{c}\text { No } \\
\text { codiciarás }\end{array}$ & & & לאט תַחְמדּד & $\begin{array}{c}\text { No } \\
\text { codiciarás }\end{array}$ & & \\
\hline & & דבית רעצֶף & $\begin{array}{l}\text { la casa de } \\
\text { tu prójimo }\end{array}$ & & & 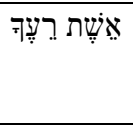 & $\begin{array}{l}\text { la mujer } \\
\text { de tu } \\
\text { prójimo }\end{array}$ \\
\hline לאו תַחְמדוד & $\begin{array}{c}\text { No } \\
\text { codiciarás }\end{array}$ & & & 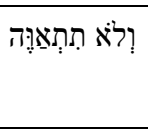 & $\begin{array}{c}\text { No } \\
\text { tendrás } \\
\text { ansia }\end{array}$ & & \\
\hline & & 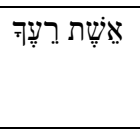 & $\begin{array}{c}\text { la mujer } \\
\text { de tu } \\
\text { prójimo }\end{array}$ & & & קבּית רֶעֶף & $\begin{array}{l}\text { la casa de } \\
\text { tu prójimo }\end{array}$ \\
\hline & & & & & & שֶָדהּוּ & $\begin{array}{l}\text { ni de su } \\
\text { campo }\end{array}$ \\
\hline & & 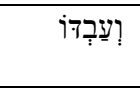 & $\begin{array}{l}\text { ni su } \\
\text { siervo }\end{array}$ & & & 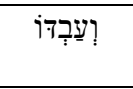 & $\begin{array}{c}\text { ni su } \\
\text { siervo }\end{array}$ \\
\hline & & 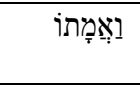 & $\begin{array}{c}\text { ni su } \\
\text { criada }\end{array}$ & & & 1ואָָמָתוֹ & $\begin{array}{l}\text { ni su } \\
\text { criada }\end{array}$ \\
\hline & & וְשוֹרוֹ & ni su buey & & & ?ןושוֹרו & ni su buey \\
\hline & & וַחְמרוֹוֹ & ni su asno & & & נוַחמרוֹוֹ & ni su asno \\
\hline & & 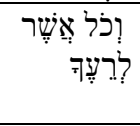 & $\begin{array}{c}\text { ni cosa } \\
\text { alguna de } \\
\text { tu prójimo }\end{array}$ & & & 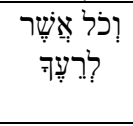 & $\begin{array}{c}\text { ni cosa } \\
\text { alguna de } \\
\text { tu prójimo }\end{array}$ \\
\hline
\end{tabular}

El pueblo hebreo, después de siglos de esclavitud en que todos sus pares son objetos se enfrenta al desierto y a la búsqueda de identidad personal y colectiva. En estos años incorpora el valor de la esposa como distintivo del valor de las cosas. En el segundo registro, la mujer sale ese espacio de las cosas aunque no deja de ser un objetivo de deseo. Después, se presentan los bienes raíces del prójimo por encima de los bienes muebles. Estos últimos se clasifican de lo humano al objeto pasando por los animales. En todos los casos es coincidente la propuesta de no solo no adulterar, matar, mentir o robar sino, además, no generar pensamientos inadecuados que tiendan hacia dichas irregularidades. Si en los principios anteriores nos encontrábamos en el marco de 
la acción exterior en estos nos hallamos ante la acción interna que produce consumismo psicosocial y trascendente.

La propuesta que Dios hace a su pueblo es la de continuar avanzando hacia una mente que, en el amor a Dios y a su prójimo, apartará progresivamente el consumismo psicosocial. El desprendimiento y la generosidad nos devuelven al espíritu del Edén, a la función natural de la persona. Cambiar la mente hacia estos valores es cambiar hacia la esperanza de un mundo renovado donde el consumo tiene su espacio, y las personas, y los animales y las cosas.

El libro del Deuteronomio expresa la oportunidad de entrar en Canaán como un pueblo que se dirige a una tierra nueva en la que mirar de nuevo a la Protología. De ahí que se planteen normativas que favorecen la gestión integral y el consumo equilibrado frente al consumismo. En este sentido, Sandra Richter presenta algunos argumentos que fortalecen el concepto de leyes ambientales en relación con el cuidado de la creación (Richter, 2010, p. 355-376; Hiers, 1996, 127-188).

a) La tierra y su producto

Indica que la tierra es un regalo divino que encuentra su explicación fundacional desde el patriarcado (Dt 1,8). Es más, no es objeto de posesión del pueblo sino una cesión divina. Dios, por tanto, tiene derecho a reclamar su posesión (Dt 29,28). Al igual que un pueblo bajo vasallaje pagaba un porcentaje de sus ganancias a sus señores, el pueblo hebreo (con la entrega de los diezmos, primicias y primogenitura). En tal práctica se halla un respeto a Yhwh como dador y poseedor de la vida (Dt 14, 22-23).

No se considera el diezmo como un impuesto sino como una celebración. Tal y como indica Dt 26, el oferente hacía memoria de sus antepasados, de cómo participó Yhwh de su historia y, entregará sus ofrendas. Tal acto se enmarca en matices de fiesta: "Luego te alegrarás de todo el bien que Jehová, tu Dios, te haya dado a ti y a tu casa, tanto tú como el levita y el extranjero que está en medio de ti” (Dt 26,11).

b) El producto y el pobre

Ya que el producto de la tierra pertenece a Dios, se sugiere que no se agote dicho producto en economías personales o nacionales. De ahí que tras el recordatorio de la buena tierra que han recibido se advierte que no deben olvidar al Dios que se la ha proporcionado (Dt 8). Además, se plantea que los bordes del campo se dejen para los desasistidos (inmigrante, huérfano, viuda). El consumo presenta un equilibrio psicosocial, considerando a aquellos que se encuentran en la marginalidad.

c) La tierra y la agricultura 
Para evitar el abuso de cultivo se establecen leyes que mantienen la fertilidad de la tierra. El núcleo esencial de estas leyes es el reposo sabático. Tal ciclo de barbecho no solo permitía que la tierra se regenerase sino que evitaba las plagas. Presenta, además, un principio de gestión: no consumir los bienes de la tierra para que sea útil en las siguientes generaciones. El crecimiento económico debía ser sostenible y el bienestar económico debía derivar de un consumo equilibrado.

d) La tierra y la guerra

Se propone cuidar la tierra incluso en tiempos de guerra (Dt 20,19). Una de las técnicas bélicas, sobre todo empleada por los asirios, era la de aniquilar los cultivos (viñedos y huertos). Con esa acción limitaban el tiempo de un sitio o impedían un posterior desarrollo económico. De ahí que los pueblos que tenían estas costumbres fueran fuertemente exterminadores de futuros recursos. La propuesta de Deuteronomio nos recuerda que ni por seguridad nacional existe la excusa para expoliar la tierra.

e) Las criaturas de la tierra

Dios, a pesar de los efectos del pecado en un mundo caído, se regocija en las criaturas de su creación. Dios ha creado en hábitat para los animales salvajes (Job 39,56.26-27). En el relato del Diluvio no solo piensa en la humanidad sino en el resto de seres vivos (Gn 9,10-11). E, incluso, se llega a celebrar la belleza del mundo salvaje en el Salmo 104.

Aunque el impacto urbanístico no era relevante, se respeta el crecimiento de las poblaciones animales. Dt 22,6-7 presenta un ejemplo de ello cuando reglamenta que no se tomen de un nido el ave y sus huevos, que se mantenga la madre. El objetivo es evitar el exterminio por medio de un consumismo biológico.

$\mathrm{Y}$ estas prescripciones hacen, obviamente, al entorno de los animales domésticos. En el mismo mandamiento relativo al sábado se recuerda que los animales vinculados a una persona deben tener su consumo adecuado de tiempo y trabajo. Los animales que iban a ser sacrificados debían responder a un protocolo en el que no se mataba sin pensar (por eso debía llevarse ante el sacerdote), y se sacrificaba con el menor sufrimiento posible. Hasta la gacela salvaje se debía sacrificar con el cuidado adecuado (Dt 12, 15.22).

En síntesis:

a) Se propone, como uno de los principios esenciales en la vida espiritual, no solo evitar la acción irregular sino los procesos mentales que derivan en tales 
acciones. El deseo psicosocial no es negativo en tanto que no se convierta en consumismo cosificador o consumismo irrefrenable.

b) La opción a la codicia y el desenfreno es el desprendimiento y la generosidad.

c) La tierra es un regalo de Dios, una cesión divina para que el pueblo hebreo realice una gestión integral. Tal gestión implica que, como "arrendatarios", se debiera devolver una parte de sus ganancias (diezmos, primicias y primogénitos) a Dios, se debiera mantener el equilibrio psicosocial con los desfavorecidos dedicándoles una parte de los cultivos, se debiera mantener la fertilidad de la tierra para las futuras generaciones, se debiera evitar prácticas de exterminio (incluso en la guerra), se debiera procurar el mantenimiento de la vida salvaje y se debiera ser respetuoso con la vida animal incluso en los ritos sacrificiales.

\subsection{Qohélet}

Si hay un libro en la Biblia que nos permite comprender la vacuidad del consumismo, ese es el de Qohélet (Eclesiastés). Al establecer la radiografía de la vanidad, identifica las principales motivaciones del deseo por lo innecesario y, por ende, de una vida consumista.

Parte de una estructura quiásmica (Dorsey, 2005) en la que se analiza la brevedad e insignificancia de la vida $\left(\mathrm{A}=1,2-11 / \mathrm{A}^{\prime}=10,20-12,8\right)$, el fracaso del conocimiento $\left(\mathrm{B}=1,12-2,26\right.$ / $\left.\mathrm{B}^{\prime}=7,15-10,19\right)$, el consumo del tiempo $(\mathrm{C}=3,1-15$ / $\left.C^{\prime}=7,1-14\right)$ y enfatiza el respeto a Dios $(3,16-6,12)$. Tal simetría concéntrica nos devuelve a la realidad de que Dios es el creador y la persona es criatura. Por ello, la vida se debe mover ante la estabilidad y fundamento de lo Alto frente a lo fugaz y volátil del consumismo biológico, psicosocial y trascendente.

El término clave en el libro de Qohélet es "vanidad" o en su traducción más literal "vapor" (הֶֶרל - hebel ). Como indica Armenteros (Armenteros, 2016b) con relación al término:

\footnotetext{
"Vapor" en la cosmovisión de la Biblia se asocia con el ciclo de la vida. El mundo primigenio es regado por un vapor que genera un ambiente edénico. Son tiempos de generosidad e inocencia, concordantes con el nombre de Abel (de la misma raíz que "vapor"). Es la esencia de la frescura y de la vida, el equilibrio y el sentido de las cosas. Pero Abel es cortado de la tierra por el agente de lo irregular, por el ansia de la pertenencia, por Caín (de la misma raíz que "posesión") y el ciclo se altera. El vapor se
} 
torna en niebla, nubes, tormentas y diluvios... Es la razón por la que Qohélet 1 comienza haciendo referencia al ciclo de la vida: las generaciones, los vientos, los astros, los ríos... los recuerdos. La memoria percibe los bucles del entorno aunque no siempre los comprenda. Es por eso que el "vapor" de Qohélet, desde esta lectura, es dual: certeza y confusión, frescor y humedad, alegría y tristeza, Abel y Caín.

Para Salomón hebel, además, es fugacidad como efecto del consumismo de los primeros seres humanos y como resultado del consumismo de los humanos de todas las épocas. El tiempo es vaporoso y atraparlo es intentar asir el aire. De igual manera que perseguir el viento es una locura, procurar el control del tiempo es una acción carente de sentido. Es, igualmente, incomprensibilidad porque el consumismo de conocimiento no es siempre fundamento de sabiduría, porque el pecado ha velado tanto la percepción como la comprensión de la existencia. Hay algo que no comprendía la mujer cuando deseó tener el conocimiento, cuando comió del fruto que habría la puerta de todas las incertezas que "la grandeza de la divinidad no cabe en este diminuto paquete de neuronas al que llamamos cerebro. Es lógico, somos criaturas y, por si fuera poco, criaturas afectadas por el pecado. Por eso, hay cosas que no entendemos". (Armenteros, 2016b) El término también hace referencia a la ilusión, a la quimera de los encandilados (Armenteros, 2016b):

Qohélet indica vez tras vez que el ser humano corre intentando atrapar el viento. Parecería una locura esta imagen si no fuera porque nos define a todos. Sí, a todos. Al que solo vive para el trabajo pensando en alcanzar una posición de privilegio. A la que se encierra en la búsqueda de la juventud a base de quirófano y bótox. Al que acumula entradas en su currículo a golpe de títulos y cursos. A la que lucha intensamente por una igualdad que la convierte progresivamente en lo que no es. Al que se obsesiona por el último gadget como si su vida pendiera de ello. A la que colecciona bolsos, zapatos o perfumes. Al que colecciona autos, relojes y corbatas. A todos.

En el sentido más actual, considerando la futilidad de las cosas, Qohélet radiografía lo hiperconsumista. Destaca lo intrascendente de lo superfluo, cuestiona la colección de cosas como si fueran vida, el amasado de dinero como si fuera esencia, el esfuerzo por el status como si fuera distintivo, el acaparamiento del tiempo como si fuera posible, el escapismo del placer como si fuera una salida y la suma de datos como si explicasen algo relevante.

En síntesis, y como indica Armenteros (Armenteros, 2016b):

Seguimos intoxicados con el virus de nuestros ancestros y nos creemos dioses. Edificamos cada vez más allá hasta que el mal de las alturas nos impide entendernos. Sin embargo, es curioso, pensamos que nuestras babeles personales son relevantes. Entonces, Salomón, nos recuerda que son nimiedades y nos molesta. Nos molesta porque nuestro ego ha crecido con nuestras construcciones y no deseamos que vuelva al 
espacio que le toca. A lo mejor Qohélet insiste en recordarnos que somos liliputienses para que comencemos un tratamiento contra el enanismo.

Y, como propuesta, nos alienta a consumir alegría. En palabras del mismo predicador: "Por tanto, alabé yo la alegría, pues no tiene el hombre más bien debajo del sol que comer, beber y alegrarse; y que esto le quede de su trabajo los días de su vida que Dios le concede debajo del sol.” (Ec 8,15)

\section{Las propuestas del cristianismo}

Todo cobra sentido a la luz de Cristo. La existencia del ser humano no solo se reviste de oportunidades sino de comprensión. Tal conocimiento aporta libertad de los factores esclavizantes y el consumo es uno de ellos. Los materiales neotestamentarios nos enmarcan en el espacio adecuado para entendernos, entender a los demás y entender el mundo que se nos ha confiado.

En primer lugar, las reacciones de Jesús contra el consumismo. En seis relatos lucanos encontramos algunas de ellas Carlson, 2010).

a) El rico insensato (Lc 12, 13-21)

Una persona pide a Jesús que intervenga en un problema de herencia y este se niega a realizar tal función. ¿Cuál es la razón? No desea mediar porque se opone a la codicia que subyace como origen de la disputa (Marshall, 1978). Sin embargo, cual rabbí, expresa su opinión sobre la avaricia y la naturaleza del hombre. Primero, advierte contra todo tipo de "avaricia" ( $\pi \lambda \varepsilon 0 v \varepsilon \xi i ́ a \varsigma$ - Pleonesias). La expresión $\pi \lambda \varepsilon o v \varepsilon \xi i ́ a$ ya la había empleado la LXX al traducir Hab 2,9; Is 28,8; Jr 22,17 y Ez 22,17 y se la había vinculado con las ganancias injustas. Jesús la identifica con una de aquellas maldades que salen de dentro y contaminan al hombre $(\mathrm{Mc} 7,19)$. Segundo, la máxima expresión

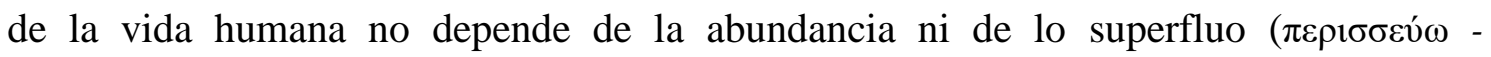
Perisseuo). Jesús emplea el término en diferentes ocasiones para referirse a lo que sobra (Mc 12,44; Lc 21,4).

La parábola presenta a cierto hombre rico que había tenido una gran cosecha y que realiza un soliloquio sobre cómo guardar aquellos productos. En sus pensamientos, de forma egoísta, sólo piensa en él y en su futuro. Sus bienes se destinarán a consumismo de índole personal: confort, comida, bebida y diversión. La parábola presenta a Dios manifestándole que esa misma noche va a morir y todo lo que tiene no le va a servir de nada. Es entonces cuando Jesús distingue entre ser rico para sí o ser rico para Dios. 
La parábola se torna en enseñanza. Nadie debe estar angustiado por los asuntos materiales porque la vida es mucho más que las cosas que la rodean. Dios que otorga la vida es quien se compromete en mantenerla de igual manera que mantiene a las aves y a los lirios. La búsqueda del reino de Dios compensa esas necesidades y otras más perentorias. Como indica Bock (Bock, 1996, p. 1168):

Jesus reminds his disciples that worry is not to be characteristic of the believer, because it is the result of a faulty view of God. A proper view of creation and God's providence illustrates the correct view. God cares for the things of nature, and yet people are more important to him than are created things. God knows what his children need and he will provide the basics of life for those who know him. Anxiety is fruitless and ultimately reflects an absence of faith. It also reflects a self-focus that inhibits one from doing God's will. Rather the disciple is to seek God's kingdom, the realization of his promises, and his will. God will bless the seeker and promises to care for him or her. The disciple is not to hoard possessions, but to use them to meet the needs of those less fortunate. Real heavenly treasure is concerned to receive God's approval, which can never pass away. When one seeks such treasure, attention will be directed not at oneself and at things that fade away, but at those who stand in need, because God has called the disciple to love others. Attachment to the God of heaven manifests itself in an absence of attachment to the things of earth. God calls the disciple not to care for things, but to care for him and the people he created. Anxiety is self-focus, but treasure - and life - is found in God and in service to others.

Mientras que el consumismo, incluso del más rico, genera ansiedad; la fe en Dios equilibra el ánimo y esclarece las perspectivas. El desasimiento del mundo de las cosas nos lleva a un apego a Dios y a las personas. La preocupación no debiera enfocarse en los objetos sino en los seres humanos, en el servicio al otro.

b) Escándalo en el banquete.

En Lc 14 nos encontramos ante una escena de banquete en que se cuestiona el consumismo psicosocial, especialmente el concepto de prestigio. Jesús observa el ansia de algunos de los invitados por ocupar los mejores lugares, espacios de mayor exposición y honra. Como indican Hendriksen y Kistemaker (Hendriksen y Kistemaker, 2001):

If rabbinic sources written somewhat later furnish a true description of dinner habits that prevailed during Christ's sojourn on earth, as they probably do, then in the room where the festive dinner was to be held the "couches for three" were arranged each in the shape of a $U$ around a low table. The central position (think of the U's curved base) of table No. 1 was considered the place of highest honor. To the left of the most highly honored person the one second in honor would be reclining; to the right of the most highly honored one the third in honor would take his place. On the three-person couch (the triclinium) to the left of the first couch the order of reclining would continue as follows: central, fourth; left of central, fifth; right of central, sixth; and so also for the 
third couch (the one to the right of the first couch); central position, seventh; left of central, eighth; right of central, ninth, etc. What Jesus noticed was this, that when the moment arrived for the guests to recline at table there was an unseemly scramble for the places of honor. This was definitely a violation of proper table etiquette. The person in charge-let us call him the host - acting on orders of the owner of the house, though often owner and host were the same person, had reserved the select seats. Not in the sense that he had placed a huge sign on them, reading reserved, but in the sense that he wanted these places to be occupied by certain definite guests, and not by other people. The fact that, in the sense indicated, these places were indeed reserved and not meant for just "anybody" is clear from verse 9. But to the mind and heart of Jesus what was happening was not merely a violation of table etiquette but a manifestation of lack of humility, as verse 11 proves.

Ante tal práctica les propone un par de parábolas (recordemos que el género del mašal va más allá de lo que comprendemos en español como parábola y que en este caso responde a ciertos consejos ante situaciones específicas). En primer lugar, si se acude a una boda no hay que colocarse en el lugar preponderante no sea que llegue alguien más importante $\mathrm{y}$ te saquen de ese sitio con la vergüenza que conlleva tal acto. Por el contrario, colocarse en un lugar de menor relevancia puede derivar en un acto de reconocimiento. El consumismo psicosocial puede derivar en pérdida mientras que el consumo equilibrado tiende hacia la verdadera ganancia. Segundo, no hay que hacer las cosas por interés personal sino por interés en los necesitados, en los anawîm (pobres, mancos, cojos, ciegos). Tal actitud conduce a la verdadera felicidad y será de recompensa en la vida venidera.

Desde este planteamiento, es relevante la reflexión de Paschall y Hobbs (Paschall \& Hobbs, 1972):

What do you think would happen to us if we actually took seriously our responsibility to follow Jesus in all areas of our lives? Suppose we started to accept and associate with people of all races, classes, and moral levels. Suppose we started to go to the kinds of places and do the kinds of things that he did. Suppose we suddenly became totally generous, completely dedicated to serving others, entirely oblivious to thoughts of selfinterest and advancement. What kind of criticism, misunderstanding, and even hatred do you think would beat against us from a scandalized society? Do you think that we would begin to understand what it means to "bear a cross" after Jesus?

c) El mayordomo infiel

Aunque Lc 16 es un verdadero crux interpretum para la teología actual, presenta dos parábolas que nos hacen reflexionar sobre la visión jesuana del consumismo. La primera de ellas, el mayordomo infiel, llega incluso a hacernos desdibujar los valores de honestidad y gestión decente con una hermenéutica inadecuada. Muchos son los comentarios que ha suscitado y sigue suscitando (Chan, 1991; Cheong, 2001; Ireland, 
1992; McDonald, 2011; Shangguan, 2013; Witt, 1985 y Zodhiates, 1983). Dos son las interpretaciones que se realizan sobre este pasaje (Marshall, 1978). La tradicional nos indica que el mayordomo tienen una conducta irregular a nivel contable en todo momento. Tal interpretación parecería apoyar una gestión corrupta y rompería toda coherencia con el mensaje de corrección que presenta Jesús. La segunda interpretación se debe a J. D. M. Derrett (Derrett, 1961, 2005) quien argumenta, basándose en los usos legales de Palestina, que el administrador había incluido el interés debido sobre los gastos diferidos y ya que la Torah prohibía el cobro de cualquier tipo de interés (así evadía la ley divina). Cuando se ve con problemas, el administrador reduce del cobro de sus clientes el monto de los intereses. De esta manera satisfacía a sus deudores y, a su vez, quedaba bien con su amo. A su vez, dejaba a un lado su propia ganancia y creaba un horizonte económico abierto. Prefiere tener amigos a tener clientes. Y esta es la actitud que alaba Jesús, el poner a las personas por encima de la rentabilidad personal. Cristo exhorta a sus discípulos a realizar un uso generoso del dinero pensando a largo plazo y en el consumo psicosocial.

d) El rico y Lázaro

A partir de Lc 16,19 nos encontramos con la parábola de Lázaro y el rico. El relato sugiere dos problemáticas. Primero, el destino de las personas en el nuevo mundo no es coincidente con el de la tierra. Ser pobre o rico no está vinculado con ser justo o impío. Segundo, no es suficiente con un cumplimiento formal de la religiosidad para ser salvo. Ni siquiera el milagro tiene esa condición. El consumismo religioso, adornado de imposturas y afirmaciones soteriológicas, es cuestionado desde su misma raíz.

La solución pasa por un ejercicio de sinceridad, de autenticidad religiosa que surge del corazón y no del bolsillo. La forma emerge de un fondo de fe, el carácter es el resultado de una vida legítima. Como indica Ellen G. White (White, 1971):

La parábola del hombre rico y Lázaro muestra cómo son apreciadas en el mundo invisible las dos clases que se representan. No hay ningún pecado en ser rico, si las riquezas no se adquieren injustamente. Un hombre rico no es condenado por tener riquezas; pero la condenación descansa sobre él si los medios que se le han confiado son gastados egoístamente. Mucho mejor sería que colocara su dinero ante el trono de Dios, usándolo para lo bueno. La muerte no puede convertir en pobre a un hombre que de esta manera se dedica a buscar las riquezas eternas. Pero el hombre que amontona para sí su tesoro, no puede llevar nada de él al cielo. Ha demostrado ser un mayordomo infiel. Durante toda su vida tuvo sus buenas cosas, pero se olvidó de su obligación para con Dios. Dejó de obtener el tesoro celestial.

e) El dignatario rico 
El relato del dignatario rico pone de nuevo en el tapete las sombras del consumismo trascendente que piensa que el cumplimiento formal de la religión le lleva por el camino adecuado. Cuando este personaje debe elegir entre sus riquezas, su estilo de vida y el desasimiento que implica seguir a Jesús, se aleja entristecido. Ante esta reacción, Cristo recuerda que es muy complicado que aquellos que están apegados a las riquezas opten por el reino de los cielos. Bock lo indica de forma bien acertada cuando expresa (Bock, 1996, p. 1483):

The importance lies in the disciples' primary commitment - to God and the path on which he calls them to walk. This path differs from person to person in particulars, but one element remains the same: God is to be trusted and to have first place (Matt. 6:24= Luke 16:13). Jesus' radical requirement is a particularly graphic way to bring the point home to this ruler. He has wrongly placed his security in his wealth, and perhaps he believes that his status is an indication of divine blessing and approval.

The ruler does not discuss Jesus' command, which shows where his true heart lies. He is not ready to come to God on God's terms. However good a teacher the ruler claims Jesus to be, his reaction shows that Jesus is not good enough to change his fundamental allegiance. At the heart of Jesus' request is a call to trust God humbly and live in reliance on God, that is, to live in light of his promise. The ruler must follow Jesus, or as 18:29 puts it "leave home and family for the sake of the kingdom of God." The demand is too much for this ruler, a point that will lead to Jesus' reflection on the ruler's actions (18:24-30).

\section{f) Zaqueo}

El relato de Zaqueo (Lc 19,1-9) entra en contraste con el relato del dignatario rico. Zaqueo solo necesita escuchar a Jesús para bajar del sicomoro. No hay más que una propuesta a invitar su casa para que se produzca el milagro. Ningún comentario a su condición laboral, ninguna recriminación a sus irregularidades económicas y, aún así, el jefe de los publicanos decide dar la mitad de sus bienes a los pobres y restituir por cuadruplicado a los que ha defraudado. El corazón de Zaqueo prefiere las personas a los bienes económicos, la justicia al abuso, la mejora de la sociedad a la posición social. Prefiere una gestión integral en Cristo que cualquier tipo de consumismo. La salvación llega a Zaqueo y a su casa porque se invierte en el lugar adecuado: el corazón. No es de extrañar que, ante tal reacción, Jesús relatara la parábola de las diez minas, una reflexión sobre la gestión humana y la expectativa divina.

Carlson sintetiza estos relatos lucanos con actualizaciones bien a tono (Carlson, 2010, p. 282-283):

What, then, does Luke have to say to us today? We are immersed in a consumer society. It assails us on a continuous basis from the ads on our television to the sidebars on the websites we visit, to the spam e-mails that arrive throughout the day and night, to the 
billboards dotting the road to work. This is a reality we cannot avoid if we have any access to the outside world. The messages to buy, get, enjoy, and devour literally consume the spaces in which we live. They are part of the fabric of our world. Luke's Gospel, however, develops a vision of God's alternative reality in which the values and standards of the world (be it either the first-century world or the twenty-first-century world) are turned upside down... In Jesus' question "Who then, is the faithful, insightful steward whom the Lord will appoint over his servants in order to give them apportionment at the critical time?" even broader questions are being asked that get at the heart of our living, stewarding discipleship. Questions such as: Do we have the Holy Spirit's insight and faithful determination to realize that resources neither belong to us nor are to be used exclusively by the privileged? Do we serve the agenda of unbridled consumerism, which ignores the needs of others but focuses its energies and expenditures on rewards for the self in this transient age? Or do we serve the agenda of God, which in the present age advances eschatological jubilee for those in need? Does our faithful, insightful stewardship empower us to trust that God will care for us in the present so that we can be compassionately extravagant in caring for others in anticipation of the divine treasure of eternal life?

Abordemos, desde lo mismos dichos de Jesús, los principios de un consumo equilibrado y de una gestión integral. Tomaremos como base el sermón de la montaña según el evangelio de Mateo (Mt 5-7) porque en él se pueden detectar los argumentos de dichos principios. Está dividido, a semejanza de los midrases homiléticos, en dos secciones. Una sección haggádica que hace a lo existencial y una sección haláquica que hace a lo nomológico. La sección haggádica se conoce tradicionalmente por el nombre de "las bienaventuranzas" y expresa la condición de necesidad de las gentes de Palestina en el siglo I. La sección haláquica presenta un paquete de matizaciones normativas que, sea por ampliación o por reducción, devuelven al sentido protológico las prácticas religiosas y sus implicaciones trascendentes.

En el siglo primero, como en la actualidad, una de las búsquedas primordiales del ser humano era la de la felicidad, la de un consumo trascendente. El anhelo de felicidad es una muestra de nuestro diseño inicial y configura los intereses más identitarios de la persona. El consumismo se embarga en compensar esta necesidad aunque solo consigue incrementar la angustia y la ansiedad. El anhelo de "felicidades alternativas" entonces, como hoy, creaba más insatisfacción que otra cosa. Como afirma Zygmunt Bauman (Bauman, 2016, p. 355):

Lo que es verdadero para la sociedad lo es para el individuo: el hombre avanza hacia un horizonte que se diluye mientras cree aproximarse, ya que toda solución plantea nuevos problemas. Hay que inventar la felicidad continuamente y nadie tiene las llaves que abren la Tierra Prometida: lo único que sabemos es pilotar con ayuda de instrumentos y rectificar continuamente, con más o menos éxito. Luchamos por una sociedad y una vida mejores, buscamos incesantemente caminos que nos lleven a la felicidad, pero ¿cómo ignorar que eso que más apreciamos, la alegría de vivir, será siempre como una propina? 
Jesús enfoca la felicidad desde los parámetros que son característicos de su enseñanza. Primero, el concepto de pertenencia. Potenciar la relación correcta con Dios, un consumo adecuado de la plataforma trascendente, aporta la percepción correcta del ser humano y su vínculo íntimo con la Deidad. Segundo, concepto de resiliencia. No hay efecto resultante del pecado que no se pueda resolver con la confianza en que Jesús es la solución, ni siquiera la muerte. Tercero, concepto de actitud. En el mensaje jesuano, la actitud es de mayor relevancia que la prosecución de obras. Las obras son el resultado de una actitud de esperanza puesto que toda renovación provendrá de Jesús en la instauración definitiva del reino de los cielos. Cuarto, concepto de acción. La acción en Cristo es la mejor gestión integral. Se toma su vida como modelo de tal acción. Quinto, concepto de esencia. La certeza de que la naturaleza de Dios se fundamenta en el amor crea una comprensión adecuada de nuestra naturaleza. Se fortalecen los valores de la vitalidad, la generosidad, el desasimiento y la benignidad frente al hedonismo, el materialismo, la cosificación y el egocentrismo.

La enseñanza de la verdadera felicidad, en las bienaventuranzas, destila estos conceptos. De forma esquemática:

\begin{tabular}{|c|c|c|}
\hline ORDEN & BIENAVENTURANZA & CONCEPTO \\
\hline A & $\begin{array}{l}\text { Bienaventurados los pobres en espíritu, } \\
\text { porque de ellos es el reino de los cielos. }\end{array}$ & PERTENENCIA \\
\hline B & $\begin{array}{c}\text { Bienaventurados los que lloran, } \\
\text { porque recibirán consolación. }\end{array}$ & RESILIENCIA \\
\hline $\mathrm{C}$ & $\begin{array}{l}\text { Bienaventurados los mansos, } \\
\text { porque recibirán la tierra por heredad. }\end{array}$ & ACTITUD \\
\hline $\mathrm{D}$ & $\begin{array}{l}\text { Bienaventurados los que tienen hambre y } \\
\text { sed de justicia, } \\
\text { porque serán saciados. }\end{array}$ & ACCIÓN \\
\hline $\mathrm{E}$ & $\begin{array}{l}\text { Bienaventurados los misericordiosos, } \\
\text { porque alcanzarán misericordia. }\end{array}$ & ESENCIA \\
\hline$D^{\prime}$ & $\begin{array}{l}\text { Bienaventurados los de limpio corazón, } \\
\text { porque verán a Dios. }\end{array}$ & ACCIÓN \\
\hline$C^{\prime}$ & $\begin{array}{l}\text { Bienaventurados los pacificadores, } \\
\text { porque serán llamados hijos de Dios. }\end{array}$ & ACTITUD \\
\hline $\mathrm{B}^{\prime}$ & $\begin{array}{l}\text { Bienaventurados los que padecen } \\
\text { persecución por causa de la justicia, } \\
\text { porque de ellos es el reino de los cielos. }\end{array}$ & RESILIENCIA \\
\hline$A^{\prime}$ & $\begin{array}{l}\text { Bienaventurados seréis cuando por mi causa } \\
\text { os insulten, os persigan y digan toda clase } \\
\text { de mal contra vosotros, mintiendo. }\end{array}$ & PERTENENCIA \\
\hline
\end{tabular}


El consumismo trascendente predica la impermeabilización de la deificación y la ausencia de adversidad. El mensaje de Jesús sitúa a la persona en su categoría de tal, por tanto, con dependencia de lo divino. Un resultado de tal pertenencia es el rechazo de los que no pertenecen a Dios, la enemistad de los adversos. El consumismo trascendente sostiene que existen diferencias sociales y que la injusticia forma parte de la realidad social. Además, que la exclusión es una vía lícita de acción. Cristo apuesta por los sensibles, por los preocupados por las personas, por aquellos que se comprometen y sufren por ello. Cristo, en todo este proceso, se ofrece como sustento, como poder mantenedor de toda resiliencia. El consumismo trascendente es afín a la violencia, sea virtual o física, al abuso del planeta y de las personas. Considera que los no violentos son débiles. Jesús afirma que la mansedumbre es la atmósfera de la gestión integral, que un abrazo tiene más fuerza que un golpe, que una sonrisa modifica más que un rictus. El consumismo trascendente considera natural la desigualdad y piensa que la inocencia es el espacio de los ingenuos, cuando no tontos. El mensaje de Cristo defiende la justicia en todos sus sentidos, aquella justicia que devuelve a la persona no solo a su condición de igual sino de autorrealizado, a la plenitud existencial. La pureza, además, es el instrumento que coloca, con una sencillez pasmosa, las cosas y las personas en el espacio que les corresponde, el espacio de la verdadera comprensión y sabiduría. Por último, el consumismo trascendente ha vaciado de contenido la semántica del amor. Jesús, por contraste, da plenitud al concepto. Propone el amor empático como eje de las relaciones psicosociales y trascendentes. No es un amor pacato y ramplón, sino un amor principio y dinámico. Un amor comprometido. Como diría Bauman: "Sin humildad y coraje no hay amor" (Bauman, 2015b).

Propuestas y conceptos que clarifican los parámetros de la felicidad anhelada.

En medio de numerosas modificaciones reglamentarias, con el objetivo de reenfocar la Torah, Jesús vuelve a plantear una renovación de consumo trascendente. Los rezos han sido, a lo largo de la historia, un indicador infalible del consumismo religioso. Han definido las expectativas humanas, las concepciones sobre lo divino y el contacto entre las aspiraciones terrenales y las espirituales. Mat 6,5-14 registra tal enseñanza. En primer lugar, cuestiona las formas del judaísmo impostado, las manifestaciones públicas y ostentosas de una religiosidad hipócrita, de un consumismo trascendente más preocupado por el prestigio que por la relación. Propone la intimidad como espacio natural de los vínculos entre Dios y la persona. En segundo lugar, rechaza los modos paganos que derivan de conceptos caprichosos de las divinidades y que 
insisten en la repetición como herramienta de "ablandamiento" de tales dioses. Jesús plantea un modelo de gestión integral de la relación entre Dios y los hombres. De forma esquemática:

\begin{tabular}{|c|c|c|}
\hline TEXTO & PLATAFORMA & CONCEPTO \\
\hline $\begin{array}{l}\text { Padre nuestro que estás en } \\
\text { los cielos }\end{array}$ & \multirow{4}{*}{ TRASCENDENTE } & $\begin{array}{l}\text { Reconocimiento de Dios } \\
\text { como Creador. }\end{array}$ \\
\hline santificado sea tu nombre. & & $\begin{array}{l}\text { Reconocimiento de Dios } \\
\text { como un ser especial. }\end{array}$ \\
\hline Venga tu Reino. & & $\begin{array}{l}\text { Petición de participación } \\
\text { de Dios en la historia de } \\
\text { los seres humanos. }\end{array}$ \\
\hline $\begin{array}{l}\text { Hágase tu voluntad, como } \\
\text { en el cielo, así también en } \\
\text { la tierra. }\end{array}$ & & $\begin{array}{l}\text { Petición de incorporación } \\
\text { del deseo divino. }\end{array}$ \\
\hline $\begin{array}{l}\text { El pan nuestro de cada día, } \\
\text { dánoslo hoy. }\end{array}$ & BIOLÓGICA & $\begin{array}{l}\text { Petición de consumo } \\
\text { biológico. }\end{array}$ \\
\hline $\begin{array}{l}\text { Perdónanos nuestras } \\
\text { deudas, } \\
\text { como también nosotros } \\
\text { perdonamos a nuestros } \\
\text { deudores. }\end{array}$ & $\begin{array}{l}\text { TRASCENDENTE / } \\
\text { PSICOSOCIAL }\end{array}$ & $\begin{array}{l}\text { Petición de posibilidad de } \\
\text { redención y de } \\
\text { interrelación } \\
\text { (Justificación). }\end{array}$ \\
\hline $\begin{array}{l}\text { No nos metas en tentación, } \\
\text { sino líbranos del mal, }\end{array}$ & \multirow{2}{*}{ TRASCENDENTE } & $\begin{array}{l}\text { Petición de posibilidad de } \\
\text { crecimiento personal } \\
\text { (Santificación). }\end{array}$ \\
\hline $\begin{array}{l}\text { porque tuyo es el Reino, el } \\
\text { poder y la gloria, } \\
\text { por todos los siglos. Amén }\end{array}$ & & $\begin{array}{l}\text { Reconocimiento de Dios } \\
\text { como autoridad } \\
\text { permanente. }\end{array}$ \\
\hline
\end{tabular}

La oración modelo se configura de proposiciones de reconocimiento y peticiones. A su vez, se sitúa en diferentes plataformas que hacen al consumo equilibrado de la vida biológica, psicosocial y trascendente. Las proposiciones de reconocimiento se centran en Dios como parte constituyente de este diálogo. Primero, reconocimiento de Dios como el generador de toda la vida. Tal constatación permite al hombre apartarse de la tentación de la deificación y enmarcarse en la posición de criatura. El empleo del término "Padre", término clave en los dichos de Jesús (Abba), además, muestra la relación de afectividad de la Deidad con sus criaturas. Hay un reconocimiento de persona y de vínculo. Segundo, un reconocimiento de la unicidad divina. Respetando la oración diaria del mundo judío, la šüma` (Dt 6,4), recuerda que Dios no solo es único sino que es especial. Tercero, un reconocimiento de que Dios participa de la historia. Participó en el pasado, y así lo expresaron los profetas. Y participa en el presente con la venida de Jesús y la llegada del reino de los cielos. El 
"tiempo del Mesías" no solo manifiesta implicación divina en la problemática humana sino que revaloriza el sentido del mismo tiempo, aportándole pasado-historia, presenteexperiencia y futuro-esperanza.

Las proposiciones de petición comienzan con el anhelo de comprender y realizar lo que a Dios le gusta. Tal apertura desplaza el eje existencial de la persona a Dios, situándole en la posición que permite comprender la mirada divina. Continúa con una petición de consumo biológico, una petición fundamentada en lo necesario que evita lo superfluo, lo meramente apetecible. Cubiertas las necesidades básica, propone la petición de perdón. Comprendiendo que solo hay redención en la actuación divina, se solicita la condonación de las culpas. Tal petición tiene el compromiso de una actitud similar en las relaciones psicosociales. La misericordia hacia el otro es el requisito para la misericordia divina. De nuevo, el eje se traslada hacia las personas que nos rodean y hacia sus realidades. A la petición de posibilidad de justificación se une la de posibilidad de crecimiento en una gestión integral. Propone que el caminar en la vida del cristiano sea en dirección distinta a la de lo irregular, de lo tendente al pecado.

Concluye, a modo de resumen, con otro reconocimiento de la autoridad constante y por siempre de Dios.

Un modelo de consumo trascendente que resitúa a la persona y la proyecta hacia el equilibrio.

De los dichos de Jesús podemos extraer algunas conclusiones:

a) La vida es mucho más que la suma de las cosas que la contienen.

b) Una cosa es ser rico para sí, experiencia momentánea que no trasciende al más allá, y otra es ser rico para Dios, proyecto de interrelación que se perpetúa con el tiempo.

c) El consumismo genera angustia y ansiedad. La confianza en Dios, sin embargo, genera tranquilidad y consuelo.

d) El apego a Dios se suele asociar con el desasimiento de las cosas.

e) Las personas están por encima de la rentabilidad personal. Son preferibles los amigos a los clientes.

f) La riqueza o la pobreza no están vinculadas directamente con la justicia o la injusticia. La autenticidad religiosa surge del corazón y no del bolsillo.

g) El consumismo no conduce a la felicidad. La felicidad se fundamenta sobre un sentido correcto de pertenencia, resiliencia, de actitud cristiana, de acción en Cristo y de amorosa esencia. 
h) Los valores cristianos de vitalidad, generosidad, desasimiento y benignidad se oponen a las propuestas consumistas de hedonismo, materialismo cosificación y egocentrismo.

i) La oración nos resitúa en la posición edénica. El reconocimiento de la naturaleza y cualidades divinas nos convierte de nuevo en seres humanos. Las peticiones nos liberan de los efectos del consumismo y son el germen de una vida de crecimiento individual.

j) Jesús se hizo persona para que conociéramos mejor a Dios como persona y para que retornáramos a nuestra condición de personas.

\section{Posibles actualizaciones}

La primera de las actualizaciones, o intuiciones de éstas, hace a nuestra cosmovisión del Metaconsumo desde unas perspectiva bíblica. La Protología nos presenta un mundo en el que el consumo es equilibrado y responde a las necesidades reales de la persona tanto desde una plataforma biológica como psicosocial o trascendente. Asociado a dicho concepto va el de gestión integral, desarrollo de la persona, cuidado de la tierra y responsabilidad sobre el resto de los seres vivos. Esquemáticamente:

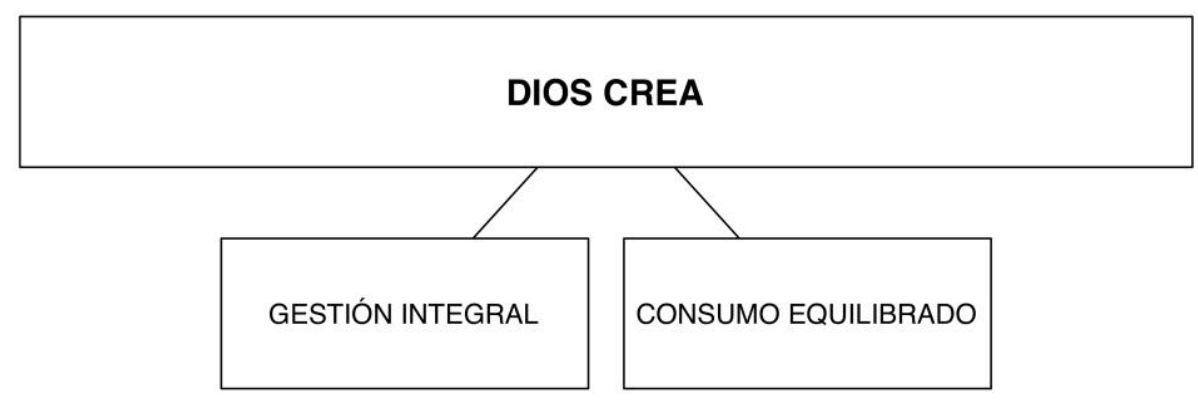

La Hamartología nos muestra un mundo caído donde se genera consumismo biológico lo que deteriora la naturaleza y la somete a la explotación por parte del hombre. El abuso es un ejercicio superfluo de tal naturaleza y, por tanto, consumismo que desequilibra. También, por el pecado, se genera un consumismo psicosocial que permite la explotación de las personas, cosificándolas y colocándolas en el espacio de la alienación. Y el consumismo trascendente que explota la religiosidad deificando las obras y gestas de los hombres y rompiendo los vínculos con la Deidad. De forma esquemática: 


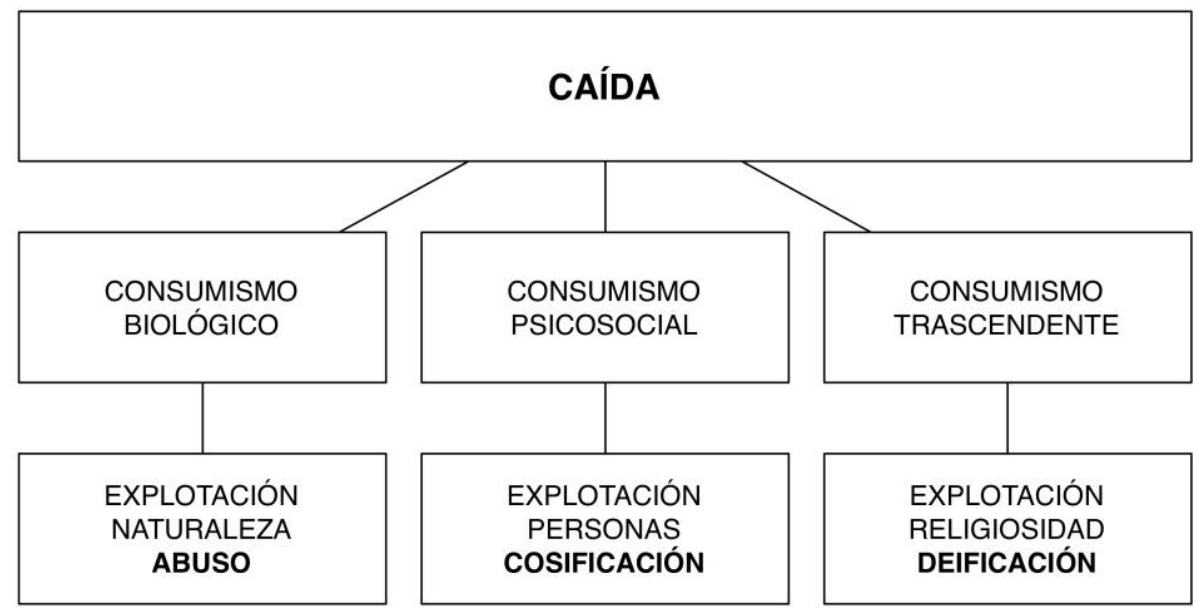

La Soteriología nos presenta la llegada de Jesús a esta tierra, como gestor integral e integrante, lo cambia todo. Coloca cada cosa en su lugar. Redime tanto a la naturaleza como a las personas como a la misma relación entre el ser humano y Dios. Bajo su administración se suprime toda actitud de abuso, de cosificación o de deificación. Sinópticamente:

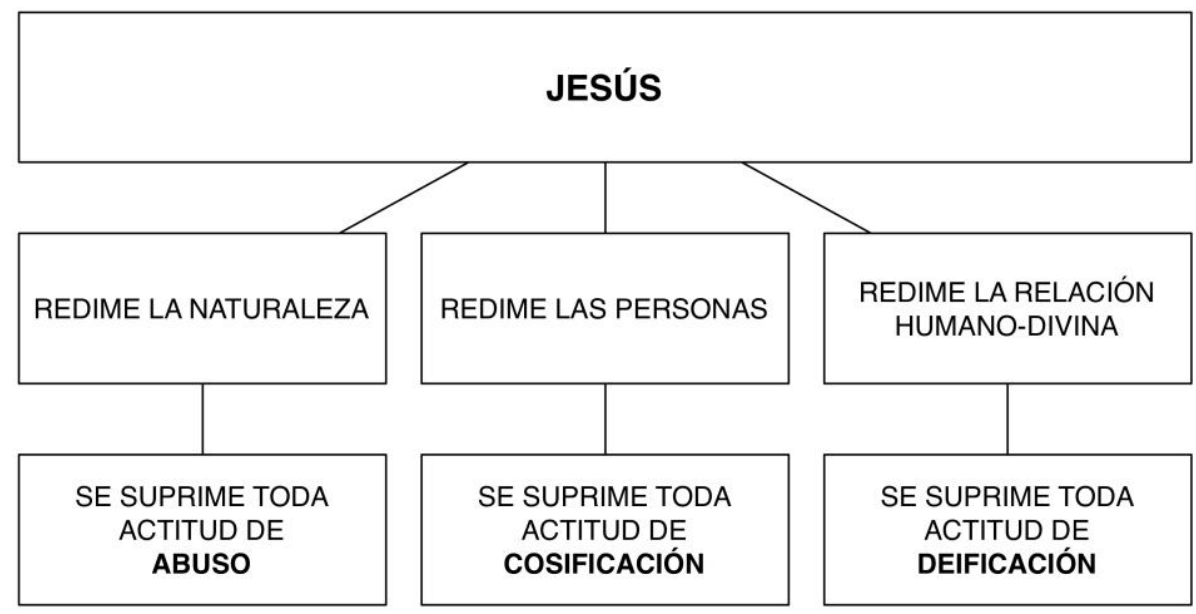

La Escatología nos permite otear el horizonte y desarrollar los fundamentos de la esperanza, el consumo trascendente más saludable. En tal situación se vislumbra la renovación de esta tierra y de sus criaturas, la renovación del ser humano (no tanto como gestor sino como habitante del reino celestial) y la renovación de los vínculos que hacen a las personas y a Dios. Sintéticamente: 


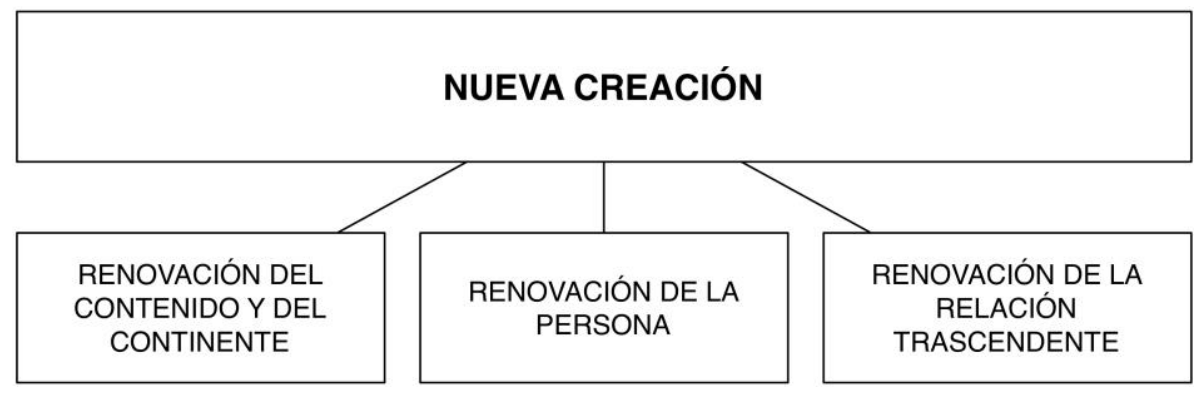

La segunda actualización, se proyecta desde esta plataforma escatológica. Dos son los textos que nos definen como iglesia del final de los tiempos. Uno identitario y otro misional.

El primero se encuentra en Ap 3, 14-22 y radiografía la iglesia de Laodicea. También podría ser una radiografía baumaniana o lipovetskiana de nuestra sociedad. El no ser ni frío ni caliente hace mucho a la apatía de la posmodernidad (Lipovetsky, 2000):

... reina la indiferencia de masa, donde domina el sentimiento de reiteración y estancamiento, en que la autonomía privada no se discute, donde lo nuevo se acoge como lo antiguo, donde se banaliza la innovación, en la que el futuro no se asimila ya a un progreso ineluctable,.. la gente quiere vivir en seguida, aquí y ahora,...

La percepción irreal de riqueza hace mucho al Narciso turboconsumidor, a la cultura del selfie de última generación. La sensación de creerse rico, desde un punto de vista consumista, es pobreza desde la cosmovisión cristiana. La angustia y la ansiedad son una muestra de dicha realidad. Es interesante que el texto (18) haga referencia al verdadero sentido de los objetos, de la moda y de la salud. Solo en Cristo se encuentra la solución a dicha situación. Una relación íntima con Él, abriendo las puertas de la actitud, nos lleva a una relación próxima al Padre, abriendo la puerta a la plenitud existencial. Volvemos al mensaje del Evangelio.

El segundo se registra en Ap 14, 6-9 y nos recuerda el mensaje a compartir en los tiempos del escaton. Comienza con un mensaje de reconocimiento de la naturaleza y acción divina. Dios es el creador y se debe recordar ese concepto en una sociedad que tiende hacia la deificación individual. Dios participa de la historia como redentor y como juez y se debe recordar ese concepto en una sociedad tiranizada por las subjetividades y microrrelatos existenciales. Continúa con un mensaje de descripción de la vida actual. El mundo sin Dios, constructor de torres de ensimismamiento, de babeles autocomplacientes se viene abajo. El mundo de confusión, constructor de caos, de 
daseins de hoy y de siempre. El mundo que retrata Luis Enrique Alonso Benito (Alonso Benito \& Fernández Rodríguez, 2013):

Una nueva forma de socialidad cargada de individualidad nos ha traído un mundo pleno de redes, tribus, organizaciones no gubernamentales, sensibilidades próximas, identidades múltiples, reflexividad creciente, reconocimiento de las diferencias, multiculturalismo, grupos de alcance intermedio y un largo etcétera, un mundo ligado a esta segunda modernidad, posmodernidad o tardomodernidad en la que estamos instalados (Wieviorka, 1997); pero no estamos exentos del peligro del individualismo solitario, desarraigado, imitativo y degradado, solo bendecido por el consumo privado, que es, paradójicamente, el fermento más poderoso, como sabemos, para la constitución de la ya hace muchísimos años conocida como sociedad estadísticamente dominante, pero rechazada tanto desde las filas conservadoras (por su destrucción de la comunidad tradicional y los valores de las jerarquías históricas) como por las teorías críticas de la sociedad por su consideración de que se asientan en un individuo insolidario, egoísta y manipulable que proporcionará un apoyo siempre seguro a los proyectos políticos abierta o soterradamente totalitarios.

Finaliza con una abierta oposición al consumismo cuando contrasta la marca de

Dios, resultante de una gestión integral en la que se respetan los diferentes consumos, y la marca de la bestia, Brand Essence del hiperconsumismo más feroz. Como indica Armenteros (Armenteros, 2017):

A lo mejor eso de Apocalipsis 14:9 iba de los seguidores del "Black Friday" frente a los seguidores del "White Shabbat". A lo mejor nos estaba anticipando dos maneras que existen de comprender el mundo. Por un lado, los que ponen el eje en ellos mismos y en sus cosas (léase egocentrismo y materialismo) y los que ponen el eje en los demás y en las personas (léase generosidad y trascendencia). A lo mejor debiéramos alegrar nuestro alma el próximo sábado porque hemos superado un viernes opacador de voluntades. Un sábado siendo más persona.

Hay un colectivo llamado a proponer que lo que es común no es lo propio, que hay otra manera de comprender a la persona que lo hace mejor, excelente. Una comunidad que apuesta por lo verdadero y que se mantiene en la promesa de la felicidad plena. Mientras tanto, el mismo Jesús nos alienta a tener el Espíritu adecuado: “Gozaos y alegraos, porque vuestra recompensa es grande en los cielos" (Mt 5,12).

\section{Referencias}

Abascal Rojas, F. (2002). Consumidor, clientela y distribución: para la economía del futuro: estudio del consumidor, análisis y valoración de la clientela: su política y política de la distribución. Pozuelo de Alarcón, Madrid: ESIC Editorial.

Aaker, D. A. y Day, G. S. (1982). Consumerism: Search for the Consumer Interest. New York: Free Press. 
Alonso Benito, L. E. y Fernández Rodríguez, C. (2013). Los discursos del presente: un análisis de los imagnarios sociales contemporáneos. Edición digital. Madrid: Siglo XXI.

Alonso Schökel, L. (1994). Diccionario Bíblico Hebreo-Español. Madrid: Trotta.

Armenteros, V.M. (2010). Amor se escribe sin h. Buenos Aires: ACES.

Armenteros, V.M. (2016a). La esencia de la Torah: El pensamiento de Midrás Tanhuma Buber al Génesis, $2^{\mathrm{a}}$ edición. Libertador San Martín: Editorial Universidad Adventista del Plata.

Armenteros, V.M. (2016b). Sauna espiritual: Reflexiones desde Qohélet. Edición digital. Gilet: Autopublicación.

Armenteros, V.M. (2017). "Black Friday or White Sabbath" Revista Adventista (21 noviembre). https://revista.adventista.es/2017/11/black-friday-or-white-shabbat/

Ballesteros. C. (2014). Taxonomía del Homo Consumens en la era 3.0. Diario el País. En línea en: https://elpais.com/elpais/2014/07/28/alterconsumismo/1406530070_140653.htm 1

Barber, B.R. (2008). Consumed: How Markets Corrupt Children, Infantilize Adults, and Swallow Citizens Whole. New York: W.W. Norton.

Bauman, Z. y Donskis L. (2015a). en Ceguera moral: la pérdida de sensibilidad en la modernidad líquida. Barcelona: Paidós.

Bauman, Z., Rosenburg, M. y Arrambide, J. (2015b). Amor líquido: acerca de la fragilidad de los vínculos humanos (México: Fondo De Cultura Económica.

Bauman, Z. (2016). Vida de consumo. Madrid: Fondo de Cultutra Económica.

Bock, D. L. (1998). Luke, 2: 9:51-24:53, Baker Exegetical Commentary on the New Testament (Grand Rapids, Mich.: Baker Books.

Brown, F., Driver, S. y Briggs, Ch. (2000). Enhaced Brown-Driver-Briggs Hebrew and English Lexicon. Edición electrónica. Oak Harbor: Logos Research Systems, Inc.

Cabal, T., Brand, Ch., OwenClendenen, E., RayCopan, P., Moreland, J. P., Powell, D. (2007) The Apologetics Study Bible: Real Questions, Straight Answers, Stronger Faith. Nashville, TN: Holman Bible Publishers.

Carlson, R. (2010). "'Who then is the Faithful, Insightful Steward?' Consumerism and Luke's Stewarding Vision”, Dialog: A Journal of Theology, 49, 4: 275-283.

Chan, H. H. (1991). The Point of the Parable of the Unjust Steward: (Luke 16:1-13) Trinity Evangelical Divinity School. 
Cheong, C. S. A. (2001). A Dialogic Reading of The Steward Parable (Luke 16:1-9) New York: Peter Lang.

Clines, D. A. J. (2011). The Dictionary of Classical Hebrew. Volumen VI. Sheffield: Sheffield Academic Press.

Collins, J. (1979). Apocalypse: The Morphology of a Genre. Missoula, MT: Society of Biblical Literature.

Cortina Orts, A. y Carreras, I. (2004). Consumo... luego existo. Barcelona: Cristianisme i Justicia, 2004.

Derrett, J. D. M. (1961). "Fresh Light on St. Luke xvi: I. The parable of the Unjust Steward", New Testament Studies, 7, 3: 198-219.

Derrett, J. D. M. (2005). Law in the New Testament. Eugene, Oregon: Wipf \& Stock.

Dorsey, D. A. (2005). The Literary Structure of the Old Testament: A Commentary on Genesis-Malachi, Grand Rapids, MI: Baker Academic.

Eliade, M. (2006). Mito y Realidad. Barcelona: Kairós, 2006.

Forte, B. (1995). Teología de la historia: ensayo sobre revelación, protología y escatología. Salamanca: Sígueme.

Freedman, D. N., Allen C. Meyers y Astrid B. Beck, Eerdmans (2000). Dictionary of the Bible. Grand Rapids, Mich.: W.B. Eerdmans.

Gage, W. A. y Bruce K. Waltke (2001). The Gospel of Genesis: Studies in Protology and Eschatology. Eugene, OR: Wipf and Stock Publishers.

Galí, J. M. (2013). Consumicidio: ensayo sobre el consumo (in) sostenible, Kindle. Terrasa: Omniabooks.

Gesenius, W. y Samuel Prideaux Tregelles (2003). Gesenius' Hebrew and Chaldee Lexicon to the Old Testament Scriptures. Bellingham, WA: Logos Research Systems, Inc.

Hendriksen, W. y Simon J. Kistemaker (2001). New Testament Commentary: Exposition of the Gospel According to Luke, New Testament Commentary, 11. Grand Rapids: Baker Book House.

Hiers, R. H. (1996). "Reverence for Life and Environmental Ethics in Biblical Law and Covenant" J.L. \& Religion 13: 127-188.

Ireland, D. (1992). Stewardship the Kingdom of God: An Historical, Exegetical, and Contextual Study of the Parable of the Parable of the Unjust Steward in Luke 16:1-13. Leiden: E.J. Brill. 
Kotler, P. (1978). Lo que significa el movimiento de los consumidores para los empresarios. Bilbao: Deusto.

Lipovetsky, G. (2000). La era del vacío. Barcelona, Editorial Anagrama.

Lipovetsky, G. (2014). La felicidad paradójica. Barcelona: Anagrama.

Marshall, I. H. (1978). The Gospel of Luke: A Commentary on the Greek Text. The New International Greek Testament Comentary. Exeter: Paternoster Press.

McCabe Baghdiantz, I. (2015). A History of Global Consumption: 1500-1800. London: Routledge.

Macdonald, M. E. (2011). The Parable of the Unjust Steward. Richmond, Va: Union Presbyterian Seminary.

Paschall, F. H. y Herschel H. H. (1972). The Teacher's Bible Commentary: A Concise, Thorough Interpretation of the Entire Bible Designed Especially for Sunday School Teachers. Nashville: Broadman and Holman Publishers.

Pereyra, M. (2011). El consumismo y la "caída de Babilonia. Apuntes Universitarios, I, 1: $59-80$.

Ragnedda, M. (2008. "El consumismo inducido: reflexiones sobre el consumismo postmoderno", Pensar la Publicidad, II, 1 124-125.

Richter, S. (2010). "Environmental Law in Deuteronomy: One Lens on a Biblical Theology of Creation Care" Bulletin for Biblical Research, 20, 3: 355-376.

Rugai, M. D. (2001). Más allá del consumismo: las necesidades humanas y el problema de los bienes. Caracas: Universidad Católica Andrés Bello.

Saad, G. (2014). The Evolutionary Bases of Consumption. New York: Psychology Press.

Saad, G. (2006). "Applying Evolutionary Psychology in Understanding the Darwinian Roots of Consumption Phenomena". Managerial and Decision Economics, 27, 2-3: 189-201.

Scragg, W. R.L. (2017) Stewardship: Resources and Responsibility. https://www.adventistbiblicalresearch.org/sites/default/files/pdf/Scragg-

Stewardship.pdf.

Shangguan, C. (2013). Examination of the Major Views of the Debt Reductions in the Parable of the Unjust Steward in Luke 16:1-13. http://www.tren.com/edocs/search.cfm?p001-1630.

Smith, J. E. (1993). The Pentateuch. 2a edición. Joplin, Mo: College Press Pub.Co.

Story, D. (2004). Defending Your Faith. Grand Rapids, MI: Kregel Publications. 
Swanson, J. (1997). Dictionary of Biblical Languages with Semantic Domains: Hebrew (Old Testament). Edición electrónica. Oak Harbor: Logos Research Systems, Inc.)

Trentmann, F. (2012). The Oxford Handbook of the History of Consumption. Oxford: Oxford University Press.

White, E.G. (1971). Palabras de vida del gran maestro. Ellen G. White State, Inc.

White, E.G. (2008). Historia de los patriarcas y los profetas. Edición electrónica. Ellen G. White State, Inc.

Witt, M. A. (1985). Study of the Parable of the Unjust Steward and Jesus' Application of It in Luke 16:1-13. Multnomah School of the Bible.

Witkowski, T.H. (2017). A History of American Consumption: Threads of Meaning, Gender, and Resistance. New York: Routledge, Taylor \& Francis Group.

Zodhiates, S. (1983). How to Manage Money: An Exegetical Exposition of the Parable of the "Unjust" Steward from the Greek Text Luke 16:1-13. Chattanooga, Tenn: AMG Publishers. 